\title{
Golden hour of neonatal life: Need of the hour
}

\author{
Deepak Sharma
}

\begin{abstract}
"Golden Hour" of neonatal life is defined as the first hour of post-natal life in both preterm and term neonates. This concept in neonatology has been adopted from adult trauma where the initial first hour of trauma management is considered as golden hour. The "Golden hour" concept includes practicing all the evidence based intervention for term and preterm neonates, in the initial sixty minutes of postnatal life for better long-term outcome. Although the current evidence supports the concept of golden hour in preterm and still there is no evidence seeking the benefit of golden hour approach in term neonates, but neonatologist around the globe feel the importance of golden hour concept equally in both preterm and term neonates. Initial first hour of neonatal life includes neonatal resuscitation, post-resuscitation care, transportation of sick newborn to neonatal intensive care unit, respiratory and cardiovascular support and initial course in nursery. The studies that evaluated the concept of golden hour in preterm neonates showed marked reduction in hypothermia, hypoglycemia, intraventricular hemorrhage (IVH), bronchopulmonary dysplasia (BPD), and retinopathy of prematurity (ROP). In this review article, we will discuss various components of neonatal care that are included in "Golden hour" of preterm and term neonatal care.
\end{abstract}

Keywords: Golden hour, Neonate, Preterm, Term

\section{Introduction}

The concept of "Golden Hour" has been introduced recently in field of neonatology, highlighting the importance of neonatal care in the first 60 minutes of postnatal life [1]. The golden hour term has been adopted from adult trauma where it is used for the initial first hour of trauma management $[2,3]$. Dr. R. Adams Cowley gave the concept of "Golden Hour" in emergency medicine and showed that with the use of golden hour approach there was decrease in patient mortality with better transport and patient outcome [2, 4]. Reynolds et al. was the first person to implement this concept in the neonatal care [1]. The neonatal management in the first hour of life have an important effect on both immediate and long-term outcomes of all neonates. There are many interventions that needs to be practiced in golden hour for neonatal care so that neonatal complications are minimized [5]. The prime objective of golden hour is to use evidence based interventions and treatment for better neonatal outcome, importantly for extremely low gestational age neonates (ELGAN) [6]. In the golden

Correspondence: dr.deepak.rohtak@gmail.com

National Institute of Medical Science, Jaipur, Rajasthan, India hour, standard approach is followed derived from the best available evidence with aim of practicing gentle but timely and effective interventions with non-invasive procedures if required [7]. In this review article, we have covered the various components of golden hour approach in preterm and term neonatal care (Fig. 1 and Table 1). The details of all the interventions with current evidence can be read from other published reviews of the author $[8,9]$.

\section{Antenatal counseling and team briefing}

Infants born at an extremely low gestational age have a high mortality rate and are at risk of having neurodevelopmental disabilities ranging from subtle to severe in grade [10-12]. Estimated gestational age of delivery has shown strong association with neurodevelopmental outcome and it serves as the basis for antenatal counselling [11], although it has some fallacies that limits its role for using as single parameter like the rate of fetal development during the early third trimester and the inaccuracy of gestational age dating. The goal of antenatal counseling is to inform parents and assist them in decisionmaking over either providing resuscitation or giving only 


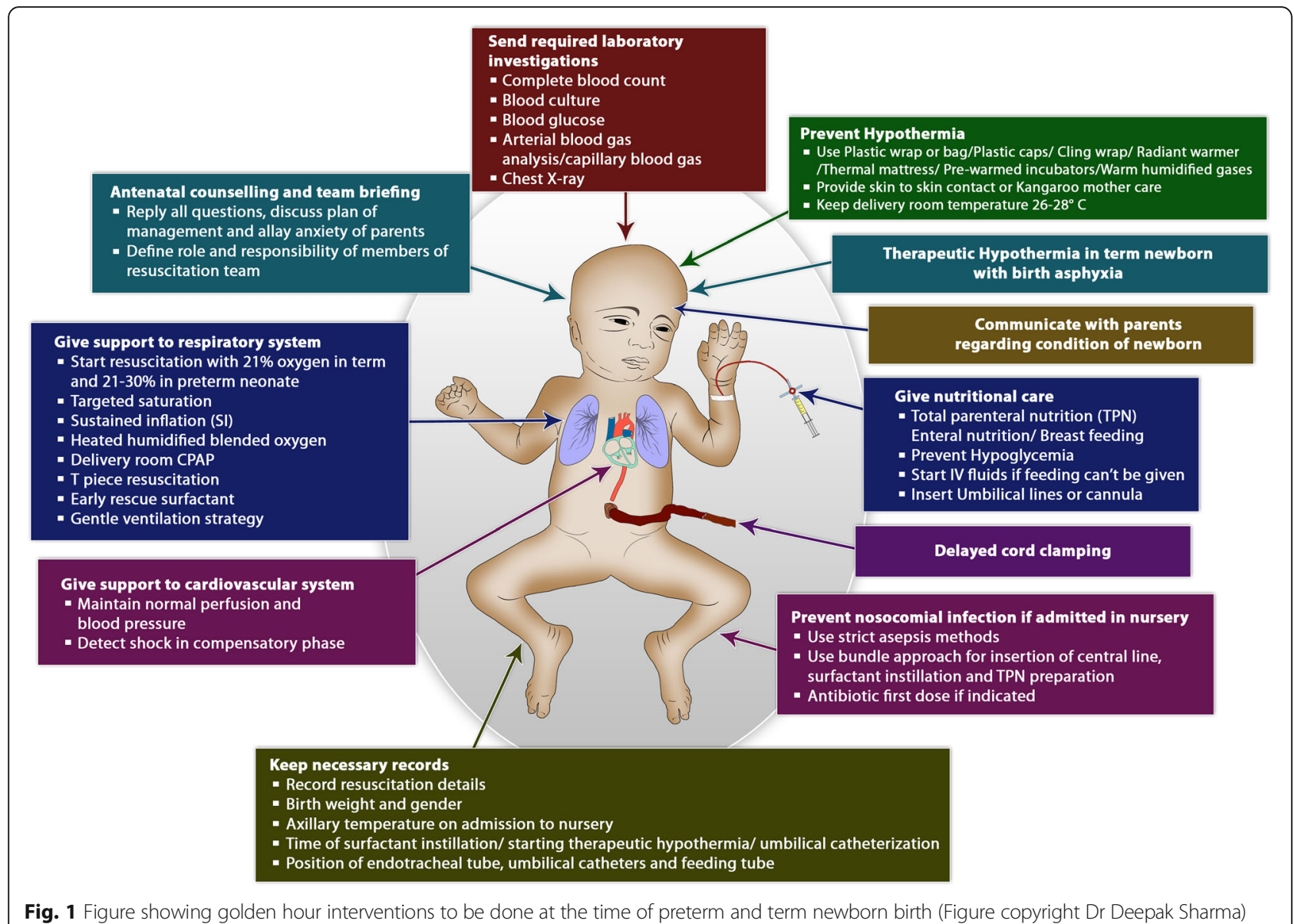

Fig. 1 Figure showing golden hour interventions to be done at the time of preterm and term newborn birth (Figure copyright Dr Deepak Sharma)

Table 1 Various components of "Golden 60 minutes" project for term and preterm newborn

\begin{tabular}{ll}
\hline S. no & Components \\
\hline 1 & Antenatal counseling and team briefing \\
2 & Delayed cord clamping \\
4 & Prevention of hypothermia/temperature maintenance \\
5 & Support to respiratory system \\
6 & Support to cardiovascular system \\
7 & Early nutritional care \\
8 & Prevention of hypoglycemia \\
9 & Initiation of breast feeding \\
10 & Infection prevention \\
11 & Starting of therapeutic hypothermia for birth asphyxia \\
12 & Laboratory investigation \\
13 & Monitoring/record \\
\hline
\end{tabular}

comfort care to the neonate. The parents can be offered comfort care for the newborn born at gestational below 25 weeks, but this decision needs to be made after consideration of region specific guidelines. The decision to provide comfort care will also depend upon the variables such as perceived accuracy of gestational age assignment, the presence or absence of chorioamnionitis, and the level of care available for location of delivery [13-15]. The three components of effective counseling are assessment of risks, communication of those risks, and ongoing support. Antenatal counselling especially before a preterm delivery has many benefits for parents like reducing parental anxiety, increasing knowledge, facilitating informed decision-making and making rapport with the neonatal clinicians $[16,17]$. In the counselling the parents should be told about most accurate prognostic morbidity and mortality data available for their infant based on hospital-specific database or regional or national data $[18,19]$. Parents also need to be informed that inspite to the best efforts, both things namely the exact prognosis or outcome for a specific infant either antenatally or immediately after delivery and prediction of long-term neurologic outcome remains limited 
[20, 21]. The parents should be given appropriate time for making decision over the neonatal management $[17,22]$. Evidence shows that rational, consensus periviability guidelines are well accepted and can be used for antenatal counselling by neonatologists, obstetricians, and nurses who provide care to pregnant women and infants at extremely low gestational ages [23].

The importance of antenatal counselling has been emphasized in neonatal resuscitation programme (NRP) 2015. The parents should be counselled antenatally, answering all the question asked by them about the newborn thus allaying there anxiety. This hold true for both pre-term and term neonate. If the newborn is going to be shifted to mother side than parents need to be counselled regarding breast feeding and general newborn care $[13,14]$ The parents should also be told about expected duration of neonatal intensive care unit (NICU) stay and morbidities which the newborn is likely to face in the postnatal life depending upon the gestational age and birth weight. The prediction of hospital stay duration will depend upon the gestational age at birth, expected morbidities and previous database of the hospital for the same gestational age neonate. The pregnancy outcome will depend upon the birth weight, gestational age, gender, use of prenatal steroids, singleton pregnancy, maternal age, maternal health, maternal nutrition, substance use, genetics, and complications during pregnancy [17, 19, 22]. The challenges of antenatal counselling includes counselling for near viability birth and fetus having antenatally diagnosed malformations. If the fetus is diagnosed with congenital malformations (e.g. congenital diaphragmatic hernia, abdominal wall defects, lung malformations, tetralogy of Fallot, hydronephrosis, or sacrococcygeal teratoma) pediatric surgeon should be brought in picture and the goal of counselling should be to inform parents regarding the implications of the fetal anomaly, reduce parental anxiety and stress and inform about the post-natal intervention like need for ventilation, hemodynamic stabilization and surgical intervention in such cases. When the fetus is diagnosed with immune hydrops fetalis than parents need to be counselled for exchange transfusion after birth and need for storage of blood antenatally so that management of the neonate is not delayed. The outcome of these neonates in such cases will depend upon the other associated malformations, lung: head ratio in case of diaphragmatic hernia, and severity of pulmonary stenosis in case of tetralogy of Fallot [24]. The parents should be counselled about the possible outcome (mortality and morbidity) keeping the past record of such newborn in the hospital [25]. Ideally both obstetrics team and neonatal team should do counselling together and present a consistent approach for the newborn as this leads to better rapport between neonatologist, obstetrician and parents.
When called for attending birth of high risk neonate than the resuscitation team should decide for the team leader and every member of the team should be given role before the delivery of the neonate so that during resuscitation there are no confusions over interventions and and thus avoiding any miss-happening. The NICU personal need to be informed for the expected neonatal admission, especially if the team is going to attend birth of any preterm neonate or high-risk term neonate. Working condition of the instruments needed during resuscitation should be checked and should be in adequate number if twins or triplets are being expected. Preresuscitation check list use make this equipment checking process very easy and rapid. Maternal history should be read in detail from the maternal records and required details should be noted down. The team who is going to attain the delivery of extreme premature, or term neonate with malformations (hydrops fetalis, congenital diaphragmatic hernia, upper airway malformation), should be expertise in attending such neonates and should have necessary skills for all interventions that may be required in the delivery room. During the time neonate reaches NICU, neonatal bed should be made ready and all required medications should be procured, thus avoiding delay in treatment once the shifting process is over $[26,27]$.

\section{Delayed cord clamping (DCC)}

Physiologically early cord clamping (ECC) have been defined as clamping of cord when still there is circulation of blood from placenta to newborn and delayed cord clamping (DCC) has been defined as clamping of cord after stoppage of placental circulation [28, 29]. When timing of cord clamping is taken in consideration for the definition of ECC and DCC, then before the mid-1950s cord clamping within one minute after birth was termed as ECC, and clamping after five minutes was defined as DCC [30]. The present studies that compared ECC and DCC, have defined ECC as cord clamping immediately or within 15 seconds of birth and DCC as cord clamping after 30 seconds to $3 \mathrm{~min}$ after neonatal birth [31-33]. The fetal-placental circulation contains blood that approximates to $110-115 \mathrm{~mL} / \mathrm{kg}$ of fetal body weight, with approximately $35-40 \%$ of total is present in the placenta at one point of time $[34,35]$. In term newborn, DCC for one-minute lead to transfer of $80 \mathrm{ml}$ extra blood and delay of three minutes leads to total transfer of $100 \mathrm{ml}$ blood to the neonate [36]. The factor that determine the placental transfusion includes cord clamping time, uterine contractions, umbilical blood flow, newborn respiration and gravity [37]. The placental flow to fetus decrease rapidly after the neonatal birth and after three minutes of birth, placental blood flow to 
neonate becomes insignificant, and by 5 minutes it absolutely ceases [38]. NRP 2015 guideline recognizes the importance of DCC in newborn and thus included new recommendations over this issue. It recommends DCC clamping (delay in cord clamping for more than 30 seconds) for all preterm and term newborn not requiring resuscitation at birth. The guidelines also further states that in newborn that requires resuscitation at time of birth, DCC should not be done till further trials are done seeking the feasibility over this $[13,14]$. The author inference from the available evidence is to delay the cord clamping for more than 30 seconds after the birth and should not be practiced in newborn requiring resuscitation. Newer beds equipped with neonatal resuscitation equipments are being made to implement the concept of DCC in newborn requiring resuscitation, although trials are still needed to see feasibility of such beds during neonatal resuscitation [39]. Cochrane meta-analysis studied the effect of timing of umbilical cord clamping and other strategies to influence placental transfusion in preterm birth on maternal and infant outcomes. This meta-analysis included fifteen studies and showed that DCC was associated with fewer infants requiring transfusions for anaemia (RR 0.61, 95\% CI 0.46 - 0.81), less intraventricular haemorrhages (IVH) (ultrasound diagnosis all grades) (RR 0.59, 95\% CI 0.41- 0.85) and lower risk for necrotizing enterocolitis (NEC) (RR 0.62, 95\% CI 0.43 - 0.90) compared with ECC. The peak bilirubin concentration was significantly higher in neonates allocated to DCC compared with ECC (mean difference $15.01 \mathrm{mmol} / \mathrm{L}, 95 \%$ CI 5.62 - 24.40) [40]. The Cochrane meta-analysis that sought the effect of DCC in term neonates reported no significant differences in neonatal mortality, Apgar score $<7$ at five minutes and neonatal admission. There was significant increase in mean birth weight in DCC (101 grams; 95\% CI 45 - 157), although neonates in DCC required more phototherapy for neonatal jaundice (RR 0.62; 95\% CI 0.41- 0.96). The haemoglobin concentration in infants at 24 to 48 hours was significantly higher in DCC group [41]. Thus the current evidence shows various beneficial effect of DCC except significant increase in requirement of phototherapy. There is still controversy over the correct time for DCC with many unresolved question and clinical issues for its successful implementation [30, 42].

There are concerns about practicing DCC in extreme premature and neonates requiring resuscitation, for which umbilical cord milking (UCM) has emerged as an alternative. In the umbilical vein alone there is approximately 15 to $20 \mathrm{~mL}$ of cord blood which can be transferred to newborn with cord milking [43]. UCM is practiced by milking $20 \mathrm{~cm}$ of umbilical cord 2 to 3 times before clamping at a rate of $20 \mathrm{~cm}$ per 2 seconds while the infant is held at or below the level of the placenta [44, 45]. The NRP 2015 guidelines are against the routine use of cord milking for newborn who are born at $<29$ weeks of gestation except in a research setting $[13,14]$.

\section{Prevention of Hypothermia}

Hypothermia defined as temperature $<36.5{ }^{\circ} \mathrm{C}$ is a dangerous problem in newborn especially in very low birth weight (VLBW), extremely low birth weight (ELBW) and ELGAN. The reported incidence of hypothermia at time of admission to the NICU in VLBW newborn ranges from $31 \%$ to $78 \%$ [46-49]. There is $28 \%$ increase in neonatal mortality with each $1{ }^{\circ} \mathrm{C}$ fall in axillary temperature while admitted in NICU [46], and admission temperature in NICU is a strong predictor for neonatal mortality $[50,51]$. The highest risk of neonatal hypothermia is within the first minutes to hours after birth as there is wide difference between inutero and environmental temperature [52]. After the birth of newborn, there is rapid loss of heat by four mechanisms namely conduction, convection, evaporation and radiation. The neonate develop hypothermia because of larger surface area per unit body weight, high surface area to volume ratio, increased evaporative fluid losses from the skin, very large surface area of head compared to body, and presence of thin layer of subcutaneous fat thus making them susceptible to easily develop hypothermia [53, 54]. Hypothermia leads to significant increase in Apgar score less than 7, IVH, late onset sepsis, hypoglycemia and respiratory distress [50]. NRP 2015 guideline recommend maintaining temperature between 36.5 to $37.5{ }^{\circ} \mathrm{C}$ and avoiding hyperthermia $\left(>37.5{ }^{\circ} \mathrm{C}\right)$ [13]. Hypothermia can be prevented by keeping delivery room temperature from 26 to $28{ }^{\circ} \mathrm{C}$, using pre-warmed linen sheets to receive the newborn just after birth, re-warming surfaces and eliminating drafts. In the delivery room and during transportation various interventions that can be practiced to prevent hypothermia are using plastic wrap or bag $[55,56]$, plastic caps, cling wrap, radiant warmer, thermal mattress [57, 58], pre-warmed single/double walled incubators [59], warm humidified gases [60, 61], and skin to skin contact $[59,62,63]$. The preterm newborn just after the birth is covered with polyethylene wrap/cling wrap or transferred into vinyl bag without drying with all necessary resuscitation steps being carried out with newborn covered in wrap. The wrap/bags is to be removed only after the newborn is shifted to nursery and is stabilized [64-70]. Plastic wraps/cling wraps/plastic caps/vinyl bags prevents heat loss by evaporation, radiant warmer prevent heat loss secondary to radiation and conduction, incubator prevent heat loss by conduction, convection, radiation and evaporation, whereas skin to skin contact and warm humidified gases acts by 
preventing conductive heat loss. The insensible fluid losses can be decreased by placing the infant in a double walled incubators like giraffe/ humidified isolette on arrival to NICU with humidification of 70-80\% [71]. NRP 2015 recommend the use of polyethylene wrap for prevention of hypothermia and early skin to skin contact in term newborn $[13,72]$. The term neonate who are stable can be dried in delivery room and hat can be placed to prevent evaporative heat loss [73]. In lower and middle income countries, NRP 2015 recommend use of clean food-grade plastic bag up to the level of the neck and skin to skin contact to prevent hypothermia $[13,14]$. Cochrane metaanalysis reported plastic wraps or bags, plastic caps, skin-to-skin care (SSC) and trans-warmer mattress being effective in reducing heat losses and reducing hypothermia [73].

\section{Support to respiration}

The goal of providing support to respiratory system is to help in the smooth transition of gas exchanging organ from placenta to lung. Support to respiratory system forms an important part of golden hour management. Both preterm and term newborn are prone to develop respiratory distress immediately after birth. Although the etiology of this respiratory distress could be varied, but the immediate goal of the neonatologist in delivery room should be in providing support to the respiratory system of these newborns [5]. NRP 2015 recommended that resuscitation of preterm newborns $(<35$ weeks of gestation) should be started with 21 to $30 \%$ oxygen, and in newborn $>35$ weeks of gestation, resuscitation should be started with room air. Use of pulse oximetry is recommended when resuscitation is anticipated, when positive pressure ventilation (PPV) is administered, when central cyanosis persists beyond the first 5 to 10 minutes of life, or when supplementary oxygen is administered. The goal of oxygen therapy is to achieve pre-ductal oxygen saturation as per the time specific interquartile range recommended in NRP (1 min 60-65\%, 2 min 65$70 \%$, 3 min $70-75 \%$, 4 min 75-80\%, 5 min $80-85 \%$ and 10 min $85-95 \%)[13,14]$ When neonates are transported to NICU and started on invasive mode than targeted saturation should be $90-95 \%$ in the preterm infants [74-77].

As per the latest NRP 2015, newborn who are born with meconium stained amniotic fluid and are vigorous (defined as having a normal respiratory effort and normal muscle tone) should be provided routine care and the infant may stay with the mother. If the newborn is not vigorous (defined as having depressed respiratory effort and poor muscle tone), the initial steps of resuscitation should be completed under the radiant warmer. Routine tracheal intubation for tracheal suctioning in non-vigorous neonate is not recommended and PPV should be initiated if the infant is not breathing or the heart rate is less than $100 / \mathrm{min}$ after the completion of initial steps. During neonatal resuscitation, endotracheal intubation is performed when bag-mask ventilation is ineffective or prolonged, when chest compressions are "anticipated" or preferably prior to onset of chest compressions, or when bag and mask ventilation is contraindicated such as congenital diaphragmatic hernia $[13,14]$. Exhaled/End tidal CO2 detection is the most reliable method of confirmation of endotracheal tube placement $[78,79]$. CO2 detector are of two type namely colorimetric devices that change color in the presence of $\mathrm{CO} 2$ (colour changes from blue/purple to yellow) and capnographs that are electronic monitors displaying the $\mathrm{CO} 2$ concentration with each breath and these detectors are attached to the ET tube. It gives false result when the infant is in cardiac arrest leading to unnecessary extubation and reintubation in critically ill newborns [80]. If there is no improvement in heart rate after effective resuscitation, chest compression and drugs or there is sudden deterioration of any infant on ventilation than suspicion of pneumothorax is kept. Transillumination test can be done in delivery room for detection of air leak syndrome [81]. If a pneumothorax causes significant respiratory distress, bradycardia, or hypotension, it should be relieved urgently by placing a catheter into the pleural space and evacuating the air. If the baby has ongoing respiratory distress, in the NICU thoracostomy tube can be inserted and may be attached to continuous suction. Pneumothorax can be prevented by avoiding giving too much inflating pressure and high PEEP during resuscitation $[13,14]$. If there is suspicion of pulmonary hypoplasia than such infants should be started on invasive ventilation with goal of gentle ventilation and hemodynamic monitoring [24].

The aim of providing early respiratory support is to achieve functional residual capacity (FRC), provide appropriate tidal volume $(4-6 \mathrm{ml} / \mathrm{kg})$ and minute ventilation, decrease work of breathing, avoid apnea, and to avoid invasive ventilation by providing assistive ventilation. The respiratory system can be supported by sustained lung inflation (SLI) [82-86], delivery room continuous positive airway pressure (CPAP) [87, 88], blended heated humidified oxygen, use of $\mathrm{T}$ piece resuscitation for providing PEEP (Peak end expiratory pressure) and PIP (Peak inspiratory pressure), early rescue surfactant (avoiding prophylactic surfactant) [75, 89-91], and use of gentle ventilation strategies [volume guarantee [92], patient triggered ventilation, permissive hypercapnia (tolerating PCo2 upto 55- 60 mmHg provided the $\mathrm{pH}>7.2$ ) [93, 94], targeted saturation (90-95\%) in preterm [75-77], avoiding hypoxia and hyperoxia, proper humidification, early extubation and using non-invasive modes of ventilation like CPAP and non-invasive mechanical ventilation (NIMV)] [95-99]. 
The goal of providing PPV is to use just enough pressure to inflate and aerate the lungs so that the heart rate and oxygen saturation increase. In the delivery room we can start PPV with PIP of 20 to $25 \mathrm{~cm} \mathrm{H2O}$ [Full-term babies may require a higher PIP for the first few breaths to inflate their lungs (30-40 $\mathrm{cm} \mathrm{H} 2 \mathrm{O}$ )], PEEP of $5 \mathrm{~cm} \mathrm{H} 2 \mathrm{O}$, respiratory rate of $40-60$ breaths/minute and $\mathrm{FiO} 2$ of $21 \%$ in $\geq$ 35 weeks and $21-30 \%$ in < 35 weeks gestational age newborn. The most important indicator of successful PPV is a rising heart rate. The adequacy of PIP is see as gentle rise and fall of the chest with each breath. If there is no chest rise than ventilation corrective steps should be done (MRSOPA=Mask adjustment, Reposition head, Suction airway, Open mouth, Pressure increase, and Alternative airway). After starting of effective PPV, monitor the baby's chest movement, heart rate, and respiratory effort. FiO2 need to be adjusted based on pulse oximetry. When the heart rate is consistently more than $100 \mathrm{bpm}$, gradually reduce the rate and pressure of PPV, observe for effective spontaneous respirations, and stimulate the baby to breathe. PPV may be discontinued when the baby has a heart rate continuously over $100 \mathrm{bpm}$ and sustained spontaneous breathing. After PPV is stopped, there is need for continues monitoring of the newborn oxygen saturation and breathing. Free-flow oxygen or CPAP may be required and can be weaned, as tolerated, based on pulse oximetry. PPV can be provided by self-inflating bag, flow-inflating bag and $\mathrm{T}$ piece resuscitator. $\mathrm{T}$ piece resuscitator requires a compressed gas source and pressure adjustment to deliver PIP and PEEP, hence need to be used in delivery room that have source of compressed gas. Its primary advantage is that it provides more consistent pressure with each breath than the self-inflating bag. It need to be use when there is need to deliver CPAP to a spontaneously breathing newborn, providing SLI and when there is need to deliver PIP also. Self-inflating bag doesn't need any source of compressed gas, hence can be used in resuscitation where there is no availability of compressed gas [86].

Sustained inflation (SLI) strategy leads to lung recruitment immediately after birth through delivery of brief peak pressure to the infant airways via a nasopharyngeal tube or mask, thus allowing preterm infants to achieve FRC. SLI leads to better alveolar recruitment, increase in pulmonary blood flow and decrease in pulmonary vascular resistance, movement of lung liquid out of the alveoli, and uniform lung expansion and better compliance [86]. After oropharyngeal and nasal suctioning, pressurecontrolled $\left(20-30 \mathrm{cmH}_{2} \mathrm{O}\right)$ inflation is sustained for 5-15 seconds, using a neonatal mask and a T-piece ventilator, followed by the delivery of $5 \mathrm{cmH}_{2} \mathrm{O}$ NCPAP. Patients is observed for the following 6 to 10 seconds to evaluate their cardio-respiratory function. If respiratory failure persists (that is, apnea and gasping) and/or the heart rate is $>60$ and $<100 \mathrm{bpm}$ despite NCPAP, the SLI maneuver (again 20-30 $\mathrm{cmH}_{2} \mathrm{O}$ for 5-15 seconds) is repeated. If the heart rate remains $>60$ and $<100 \mathrm{bpm}$ after the second SLI maneuver, the infant is resuscitated following the current guidelines of the NRP $[82,83,85,100,101]$. The European Resuscitation Council Guidelines recommend SI for the initial ventilation of apneic term and preterm infants [102].

In a ventilated infant Oxygen saturation index $(\mathrm{OSI}=$ Mean airway pressure $\times \mathrm{FiO} 2 \times 100: \mathrm{SpO} 2)$ is an noninvasive method to assess severity of hypoxic respiratory failure, acute respiratory distress syndrome or acute lung injury [103]. OSI of 6.5 equals to the acute lung injury criteria, and an OSI of 7.8 equals to acute respiratory distress syndrome criteria [104]. The goal of invasive ventilation should be minimizing lung injury secondary to ventilation namely barotrauma, volutrauma, atelectotrauma, biotrauma and rheotrauma [92, 94, 105]. Volume targeted mode of ventilation has shown to cause reduction in the combined outcome of death or BPD, pneumothorax, hypocarbia and the combined outcome of periventricular leukomalacia or grade 3-4 IVH, thus making it a preferred mode over pressure control mode in neonatal ventilation $[92,106]$. When nasal CPAP is compared with nasal intermittent positive pressure ventilation (NIPPV) as primary mode of respiratory support, NIPPV has found to superior to NCPAP for decreasing respiratory failure and the need for intubation and endotracheal tube ventilation among preterm infants with respiratory distress syndrome (RDS) [107]. Similarly for post-extubation respiratory support, NIPPV has shown to be superior over NCPAP in reducing the incidence of extubation failure and the need for re-intubation within 48 hours to one week [108]. Any wrong intervention done in golden hour leads to damage of the lung parenchyma, and plays an important role in development of bronchopulmonary dysplasia (BPD) in ELBW, VLBW or EGLAN [109].

Preterm neonates are born with less surfactant pool and the use of surfactant in the management of respiratory distress syndrome has revolutionized care of the preterm infants. Animal derived surfactant is preferred over protein free synthetic surfactant as it leads to greater early improvement in the requirement for ventilator support, fewer pneumothoraxes, and fewer deaths [110]. When protein containing synthetic surfactants was compared with animal derived surfactant, results of the study showed equal efficacy [111]. Surfactant should be given as "early rescue" i.e. within two hours of neonatal birth and is preferred over "late rescue" with simultaneous respiratory system support in form of either invasive ventilation or non-invasive ventilation depending upon the clinical condition of the infant [112]. The indication for giving surfactant are preterm infants born at $<30$ weeks' gestation who need mechanical 
ventilation because of severe RDS and infant showing signs of RDS and need more than 30\% inspired oxygen to maintain saturations in the normal range [75]. Surfactant should be administered in the standard method of aliquots instilled into an endotracheal tube. There are multiple method of surfactant administration namely administration through catheter, side port, or suction valve; administration through dual-lumen endotracheal tube; administration through a laryngeal mask airway; nasopharyngeal administration of surfactant and INSURE. INSURE (INtubation SURfactant administration and Extubation to CPAP) is the preferred method of surfactant installation if the infant has good respiratory efforts $[113,114]$. The complications of surfactant administration includes transient airway obstruction, oxygen desaturation, bradycardia, and alterations in cerebral blood flow and brain electrical activity [115]. Early surfactant replacement therapy with extubation to NCPAP compared with later selective surfactant replacement and continued mechanical ventilation with extubation from low ventilator support has shown to be associated with less need mechanical ventilation, lower incidence of BPD and fewer air leak syndromes [116]. With the use of delivery room CPAP, using "prophylactic surfactant" i.e. surfactant installation within 15 minutes of birth is not recommended in clinical practice [91]. Recently there has been research in less invasive surfactant administration (LISA) and studies have shown that it leads to lower rates of mechanical ventilation, postnatal steroids, BPD and BPD or death than the controls [117-119].

Airway obstruction is a life-threatening emergency and needs immediate management. The newborn's airway may be obstructed by thick secretions or a congenital anomaly that leads to an anatomic obstruction. If newborn with Pierre robin sequence develops labored breathing, he is turned prone on his stomach. In this position, the tongue move forward and open the airway. If prone positioning is not successful, small endotracheal tube $(2.5 \mathrm{~mm})$ is inserted through the nose with the tip placed deep in the posterior pharynx, past the base of the tongue, and above the vocal cords. It is not inserted into the trachea and there is no requirement of laryngoscope. This helps in relieving the airway obstruction. In these newborn who develop severe difficulty in breathing and requires resuscitation, face-mask ventilation and endotracheal intubation may be very difficult and laryngeal mask may provide a lifesaving rescue airway. In newborn choanal atresia is usually unilateral and does not cause significant symptoms in the newborn period. Newborn with bilateral choanal atresia may develop respiratory distress immediately after birth. The mouth and airway can be kept open by inserting one of the following into the baby's mouth-a feeding nipple or pacifier modified by cutting off the end (McGovern nipple) and secured with ties around the occiput, an oral endotracheal tube positioned with the tip just beyond the tongue in the posterior pharynx, or a plastic oral (Guedel) airway. In newborn with congenital high airway obstruction (CHAOS), then there is need for special expertise and equipment for successful intubation. If the obstruction is above the level of the vocal cords than placement of a laryngeal mask may provide a lifesaving rescue airway. If the obstruction is below vocal cords than there will need for emergency tracheostomy, therefore if CHAOS is diagnosed antenatally than such babies should be born in a facility where emergency management of the airway by a trained multidisciplinary team is immediately available in the delivery room $[13,14]$.

The clinical course of respiratory distress also helps in differentiating the various cause of distress. In RDS there is onset of respiratory distress immediately after birth followed by gradual worsening of distress over next six hours. In air leak syndrome there will be sudden onset of hypoxia and hypercarbia, chest hyperinflation and reduced air entry. In neonate with PPHN there will be severe cyanosis, extreme liability especially on handling, tricuspid systolic murmur and differential saturation of pre-ductal and post-ductal. In MAS there will cord stained of meconium in term or post-term neonate, tachypnea, hypoxia, barrel shaped chest and PPHN. Chest X-ray done in NICU will also further help in diagnosing the etiology of respiratory distress $[120,121]$.

\section{Support to cardiovascular system}

The goal of giving support to cardiovascular system is to have normal capillary refill time (For 5 seconds, finger is pressed over sternum to have blanching of skin and then count seconds to see disappearance of blanching, consider abnormal when it is $\geq 3$ second), heart rate and blood pressure in both preterm and term newborn [122]. The first parameter that shows effectiveness of resuscitation is improvement in heart rate. To assess the response to initial steps of resuscitation, auscultation along the left side of the chest is the most accurate physical examination method of determining a neonate's heart rate. Estimation of the heart rate is done by counting the number of beats in 6 seconds and multiplying by 10. If the newborn requires PPV during resuscitation than assessment of heart rate is done using 3 lead ECG, which is more reliable than pulse oximetry for detection of heart rate. Thus as per NRP 2015 during resuscitation of term and preterm newborns, the use of 3-lead ECG is recommended for the rapid and accurate measurement of the newborn's heart rate $[13,14]$. The interventions that may be needed in delivery room for supporting cardiovascular system includes bag and mask ventilation, intubation and PPV, chest compression and rarely drugs (normal saline and adrenaline). Venous access should be 
established at the earliest with umbilical vein being the easiest vein to be cannulated through which medicines are given. Umbilical venous catheter (UVC) is inserted for 2 to $4 \mathrm{~cm}$ (less in preterm babies) until there is free flow of blood [13]. The medicine are required during resuscitation when inspite of effective ventilation and chest compression, the newborn still have a heart rate below $60 \mathrm{bpm}$. The medicine required during resuscitation are epinephrine and normal saline $(0.9 \% \mathrm{NaCl})$. Epinephrine is given if the newborn heart rate remains below $60 \mathrm{bpm}$ after 1) At least 30 seconds of PPV that inflates the lungs (moves the chest), and 2) Another 60 seconds of chest compressions coordinated with PPV using 100\% oxygen. The recommended intravenous or intraosseous dose is 0.1 to $0.3 \mathrm{~mL} / \mathrm{kg}$ (equal to 0.01 to $0.03 \mathrm{mg} / \mathrm{kg}$ ) for $1: 10,000$ dilution. If epinephrine is to be given by endotracheal pathway, than the recommended dose is 0.5 to $1 \mathrm{~mL} / \mathrm{kg}$ (equal to 0.05 to $0.1 \mathrm{mg} / \mathrm{kg}$ ) for $1: 10,000$ dilution. Newborns with hypovolemic shock from acute blood loss (eg, acute feto-maternal hemorrhage, bleeding vasa previa, extensive vaginal bleeding, fetal trauma, cord disruption, umbilical cord prolapse, and severe cord compression) may require emergency volume expansion. These newborn have features of shock like pale in color, delayed capillary refill, and/ or weak pulses. Packed red blood cells should be considered for volume replacement when severe fetal anemia is suspected. If cross-matched blood is not immediately available, then non-crossmatched, type-O, Rh-negative packed red blood cells are used. The initial dose of the selected volume expander is $10 \mathrm{~mL} / \mathrm{kg}$ that needs to be given as a steady infusion over 5 to 10 minutes, followed by repeat dose if the newborn does not improve after the first dose $[13,14]$.

The causes of shock in preterm and term newborn includes prematurity (secondary to poor vasomotor tone, immature myocardium that is more sensitive to changes in afterload and dysregulated nitric oxide production), asphyxia, early onset sepsis (EOS), air leak syndromes, myocardial dysfunction, hypovolemia, maternal anaesthesia, fetal arrhythmias and fetal blood loss (ante-partum hemorrhage, feto-maternal hemorrhage or twin to twin transfusion syndrome) [123]. Arterial blood pressure (BP) is the most frequently monitored indicator of neonatal circulatory status but studies has shown that systemic perfusion shows poor correlation with BP [124, 125]. Groves et al. showed that in infants with reduced systemic perfusion, BP tends to have normal or high values in the first hours of life and low BP didn't correlated with poor perfusion in the first $48 \mathrm{~h}$ of postnatal life in sick preterm infants [126]. Lactate measurement can be done in blood gas and it is used as biomarker in diagnosing and assessing the severity of systemic hypoperfusion and can help in earlier diagnosis of shock in normotensive neonates during golden hour [127].The neonatologist should identify shock in compensated phase and should manage it aggressively. The management includes establishing early intravenous access, judicious use of fluid resuscitation, vasopressors (dopamine or dobutamine) and other supportive care like blood transfusion for hemorrhage, and antibiotics for septic shock [122, 128].

ELBW/EGLAN and VLBW are prone to have IVH during postnatal life, and of the total IVH 50\% take place on day 1 of post-natal life. Indomethacin prophylaxis has been used to reduce incidence of IVH in premature neonates [129]. Trial of Indomethacin prophylaxis in preterms (TIPP) trial which is the largest study conducted to see the effect of Indomethacin prophylaxis in ELBW reported that prophylactic indomethacin lead to the reduction in the incidence of PDA, PDA ligation, IVH (grades 3 and 4 ), and pulmonary hemorrhage $[16,18]$, but there was no reduction in the incidence of death or neurodevelopmental abnormalities [130]. Cochrane meta-analysis that included 19 trials concluded that prophylactic indomethacin reduced the incidence of symptomatic PDA, PDA surgical ligation and incidence of severe IVH but there was no effect on mortality or on a composite of death or severe neurodevelopmental disability assessed at 18 to 36 months old [131]. Hence, indomethacin is not recommended for routine prophylaxis against IVH. However, indomethacin is still being used in some neonatal units depending on clinical circumstances and personal preferences [132].

As traditional clinical and biochemical markers of perfusion have little importance in the neonatal population, therefore bed side functional echocardiography (FE) has come in picture and is used as point of care in the golden hour to find out the cause of shock and help in the management of neonatal shock. FE helps in the assessment of function of the circulatory system rather than detailed anatomy and help in rapid decision making based on real time images of central blood flow [133, 134]. Assessment of superior vena cava (SVC) flow using FE has shown to the best available method of monitoring central perfusion in the neonatal population and flow within the SVC has been considered as a good surrogate marker of cerebral perfusion [135, 136]. Thus SVC flow can be assessed in neonates who are in shock or having perinatal asphyxia [137, 138].

Persistent Pulmonary Hypertension (PPHN) is also seen sometimes in sick neonates during the golden hour. PPHN is due to increased pulmonary vascular resistance or supra-systemic pulmonary pressure leading to rightto-left shunting of blood across patent foramen ovale (PFO) and patent ductus arteriosus (PDA) leading to hypoxemia [139]. PPHN is result of either maladaptation of lung parenchyma, maldevelopment of pulmonary vasculature, underdevelopment of pulmonary vasculature or 
intrinsic obstruction in the pulmonary vasculature. The clinical presentation of PPHN includes labile saturations, hypoxemia, high Fio2 requirement, predominant tachypnea, saturation difference ( $>5-10 \%)$, or $\mathrm{PaO} 2$ differences (10-20 $\mathrm{mmHg}$ ) between right upper limb and lower limbs. Echocardiography is gold standard to confirm the diagnosis, and should be performed when suspicion of PPHN is there. Right to left shunting across PDA and PFO, flattening or left deviation of the interventricular septum and tricuspid regurgitation are suggestive of PPHN [140]. The management of PPHN includes optimal oxygenation, avoiding respiratory and metabolic acidosis, normoglycemia, normal metabolic milieu, blood pressure stabilization, sedation, inhaled or intravenous prostacyclin, intravenous prostaglandin E1, pulmonary vasodilator therapy (selective like Nitric Oxide and non -selective like Sildenafil and Milrinone) and extracorporeal membrane oxygenation (ECMO). Left to right shunting at both PDA and PFO level in the golden hour should be managed with optimal lung recruitment (providing adequate PEEP) and surfactant if there is parenchymal disease. Left to right shunting at PDA and right to left shunting at PFO level indicates ductal dependent right sided heart lesion and needs Prostaglandin E1 infusion, whereas vice-versa shunting across PFO and PDA shows ductal dependent left sided heart lesion and needs Prostaglandin E1 infusion and Milrinone [141-143].

\section{Support for nutrition}

In-utero placenta provides necessary nutritional support to the fetus and as the umbilical cord is cut, the supply of nutrition is also interrupted. This makes providing support to nutrition for both term and preterm newborn a priority. In case of term newborn with no contraindications of feeding, breast feeding should be started within half hour of birth. NRP 2015 and Baby Friendly Hospital Initiative (BFHI) guidelines recommend stable newborn babies to be kept in SSC contact with mother immediately after birth and breast feeding should be done within the first half-hour following birth $[13,14,144]$. In ELBW, VLBW, EGLAN or term neonates, whom immediately feeding cannot be started, nutritional requirements needs to be taken care of. The fluid requirement of the newborn will depend upon the gestational age, and sensible/insensible water loss. The goal of fluid replacement is to provide adequate calories, protein and lipids; and compensate for the ongoing fluid losses [145]. In newborn infants the starting fluid on day 1 for birth weight $<1000$ gram is $100-150 \mathrm{ml} / \mathrm{kg} /$ day, $1000-1500$ gram is $80-100 \mathrm{ml} / \mathrm{kg} /$ day and for $>1500$ gram is $60-80$ $\mathrm{ml} / \mathrm{kg} /$ day. Fluid restriction is done when there is decreased weight loss $(<1 \% /$ day or a cumulative loss $<5 \%)$, decreased serum sodium in the presence of weight gain $(\mathrm{Na}<130 \mathrm{meq} / \mathrm{dl})$, decreased urine specific gravity $<1.005$ or urine osmolality $<100 \mathrm{mosm} / \mathrm{L}$ and increased urine output ( $>3 \mathrm{ml} / \mathrm{kg} / \mathrm{hr}$ ) [146]. The results from various studies have shown that restricted water intake has a beneficial effect on the incidence of PDA, BPD, NEC and death [147]. Hyponatremia with weight loss suggests sodium depletion and needs sodium replacement. Hyponatremia with weight gain suggests dilutional hyponatremia and requires fluid restriction. Hypernatremia with weight loss suggests dehydration and management includes fluid correction over 48 hours. Hypernatremia with weight gain suggests salt and water load and needs fluid and sodium restriction [148]. The daily protein and lipid requirement in ELBW/VLBW neonates is around $4-4.5 \mathrm{gm} / \mathrm{kg} / \mathrm{day}$ and $3 \mathrm{gm} / \mathrm{kg} /$ day respectively [149-151]. The venous access should be secured in these newborn and intravenous fluids should be started at earliest to prevent hypoglycemia. The VLBW/ELBW/ELGAN newborn should be started on total parenteral nutrition (TPN) (dextrose, lipids and protein) with in the first hour of post-natal life [152-154]. The stable preterm who don't have any contraindication of enteral feedings should be started on enteral feeds within golden hour with preference to mother milk or donor human milk [155]. The newborn who are born with surgical conditions like gastrochisis and omphalocele needs stabilization in delivery room. Sterile silastic bowel bags and/or saline-soaked gauze dressings are used to prevent damage to the exposed intestines. Handling of the bowel is minimized to prevent vascular compromise. A nasogastric tube is placed to decompress the stomach and bowel. Such newborns are sometimes born with clinical features of shock, thereafter fluid resuscitation with isotonic solutions such as normal saline or Ringer's lactate is recommended. Maintenance fluids are started (2-3 times of normal maintenance) to compensate for increased fluid loss and third space deficit. Broad-spectrum antibiotics are begun prophylactically. Any metabolic acidosis is corrected, and urgent surgical consultation is obtained [156].

The newborn who are at high risk for developing hypoglycemia after birth are premature, intrauterine growth restricted [157], sick, low birth weight, infant of diabetic mother, late preterm, large for gestational age and birth asphyxia. The neonates who are sick and have risk factor to develop hypoglycemia should get glucose level measured in golden hour [158]. The goal is to keep glucose level $50-110 \mathrm{mg} / \mathrm{dl}$ and hypoglycemia should be managed with feeding, or dextrose infusion (glucose infusion rate (GIR) is calculated and infusion is started at GIR of $4-6 \mathrm{mg} / \mathrm{kg} / \mathrm{min}$ in preterm and $6-8 \mathrm{mg} / \mathrm{kg} / \mathrm{min}$ in term neonates and increased gradually to $12 \mathrm{mg} / \mathrm{kg} /$ min) as per the clinic condition of the newborn and 
symptoms of hypoglycemia [159, 160]. Symptomatic hypoglycemia (irritability, stupor, jitteriness, tremors, apathy, episodes of cyanosis, convulsions, intermittent apneic spells or tachypnea, weak and high pitched cry, limpness and lethargy, difficulty in feeding, and eye rolling) or glucose level $<25 \mathrm{mg} / \mathrm{dl}$ needs to be managed with bolus of $10 \%$ dextrose at $2 \mathrm{ml} / \mathrm{kg}$ followed by continuous glucose infusion at GIR of $6-8 \mathrm{mg} / \mathrm{kg} / \mathrm{min}$. Blood sugar should be checked again after 20-30 minutes after bolus and then and then hourly until stable, to determine if additional bolus is required [161-163]. The infants who generally need GIR $>8 \mathrm{mg} / \mathrm{kg} / \mathrm{min}$ are usually severe IUGR or else having congenital hypopituitarism, adrenal insufficiency, hyperinsulinemic states, galactosemia, glycogen storage disorders, Maple syrup urine disease, Mitochondrial disorders and Fatty acid oxidation defect [164]. Recently oral $40 \%$ dextrose gel used in the management of hypoglycemia has shown to reduces the incidence of mother-infant separation for treatment and increased the likelihood of full breast feeding after discharge compared with placebo gel [165]. Hyperglycemia (defined as blood glucose level $>125 \mathrm{mg} / \mathrm{dl}$ or plasma glucose level $>145 \mathrm{mg} / \mathrm{dl}$ ) is also possible in golden hour. Hyperglycemia is managed by reducing the GIR and exogenous insulin is used when glucose values exceed $250 \mathrm{mg} / \mathrm{dL}$ despite decreasing GIR or when prolonged restriction of parenterally administered glucose would substantially decrease the required total caloric intake [166].

\section{Prevention of sepsis}

Neonatal sepsis and prematurity are the two most common cause of neonatal mortality and morbidity [167-169]. The clinical manifestations of neonatal sepsis are varied and needs high degree of suspicion for early diagnosis of neonatal sepsis [170-175]. Many intervention are done to prevent neonatal sepsis, but the most important are hand washing and using asepsis precautions while handling the newborn [176-180]. The newborn should be handled with strict asepsis techniques starting from the time the neonatal birth. All invasive procedures like umbilical line or peripheral cannula insertion, administration of surfactant, preparation of IV fluids, TPN, and antibiotics should be done using aseptic precautions and bundle approach should be used [181-184]. CPAP/ventilator tubing should be sterilized and sterile distill water should be used for humidification. The newborn whom antibiotics needs to be started secondary to risk factor for early onset sepsis (EOS), first dose of antibiotic need to be given as per the unit policy in the golden hour and blood culture should be sought using aseptic precautions [1]. The risk factor for EOS includes leaking per vaginum $>18$ hours; maternal features of chorioamnionitis like maternal fever, maternal tachycardia, maternal leukocytosis, foul smelling liquor, uterine tenderness, and fetal tachycardia; $\geq 3$ clean vaginal examination or single unclean examination; and maternal urinary tract infection in last two weeks [185]. Placental pathological examination has also been used to confirm histologic chorioamnionitis which is defined as presence of inflammatory cells in the fetal membranes [186, 187]. Organism can be isolated by culture or PCR of the placenta, but placental cultures may be negative, even in the presence of overt histologic inflammation, thus making role of culture in diagnosis of chorioamnionitis doubtful [188]. In developing countries the most common organism responsible for early onset sepsis are Klebsiella spp., Enterobacter spp., Escherichia coli and Coagulase Negative Staphylococci [170, 189], whereas in developed countries Group B Streptococci (GBS) is most common in term, and Escherichia coli is most prevalent among premature infants [190-192]. The antibiotic therapy should be directed toward the most common causes of neonatal sepsis, including intravenous ampicillin for GBS and coverage for gram negative organisms (Aminoglycoside) and antibiotic decision should also take into consideration local antibiotic resistance patterns [193]. The total duration of antibiotics will depend upon the clinical status, results of sepsis screen and blood culture. If the blood culture shows growth of organism, antibiotics should continue for next 10-14 days; if the blood culture is sterile, sepsis screen is normal and the neonate is clinically well, antibiotics should be stopped after 48 hours and if the blood culture is negative and the neonate is well, but the sepsis screen is abnormal, then empirical antibiotics are continued for 5-7 days [194-197]. Lumbar puncture done for cerebrospinal fluid culture, biochemical and microbiological analysis is usually not recommended as routine investigation for early onset sepsis screening and it should to be done in neonates whose blood culture is positive, infants with a strong clinical suspicion of sepsis or neonate present with seizure activity, apnea, and depressed sensorium [198]. There is no role of CRP measurement in golden hour as half-life of CRP is 24 to $48 \mathrm{~h}$ and it takes around 10 to $12 \mathrm{~h}$ for level to increase, thus making CRP measurement in golden hour unreliable [199].

Fungal prophylaxis has shown to cause significant reduction in incidence of invasive fungal infection in very preterm or VLBW infants [200]. All ELBW/VLBW neonates can be started on fluconazole prophylaxis within golden hour provided the incidence of fungal sepsis is significant in the neonatal care unit $(>5 \%$ at baseline) [201]. On the other hand European guidelines suggest that $2 \%$ incidence of fungal sepsis should be the threshold for implementing a fluconazole prophylaxis [202].

Mother are also sometimes infected with various viral infection at the time of neonatal birth. Such neonates needs to be managed in golden hour as per the viral 
infection of the mother. The neonate who are born to mother with active herpes simplex virus (HSV) genital lesions should be evaluated at 24 hours of postnatal life with HSV surface cultures (and PCRs if desired), HSV blood PCR, CSF cell count, chemistries, and HSV PCR and serum alanine transferase and should be either started on acyclovir or observed till the results of the initial tests [203, 204]. The clinical manifestation of neonatal HSV depends upon the time of acquiring infection with HSV. In-utero or congenital HSV infected neonate presents with triad of clinical manifestations at birth a). cutaneous (active lesions, scarring, aplasia cutis, hyperpigmentation or hypopigmentation) b). neurological (microcephaly, intracranial calcifications, hydranencephaly) c). ocular (chorioretinitis, microphthalmia, optic atrophy). Neonatal HSV infection acquired during the peripartum or postpartum period manifest in three forms namely Skin, eyes and mucocutaneous disease (SEM) disease [involve skin, eye, or mucocutaneous membranes]; Central nervous system (CNS) disease [involve CNS and may also have mucocutaneous involvement, but no evidence of any other organ system involvement] and disseminated disease [involve multiple organ systems including the liver, lungs, adrenals, gastrointestinal tract, CNS and the skin, eyes, or mouth] $[204,205]$. The infants born to mother infected with Hepatitis-B should receive Hepatitis B immunoglobulin and single-antigen hepatitis $B$ vaccine within 12 hours of birth. The infants who are born to HIV positive mother should be either started on exclusive breast feeding or formula feeds after discussing with parents and explaining them to avoid mixed feeding. The infants also need to be started on antiretroviral (ARV) prophylaxis with either Zidovudine or Nevirapine [206, 207].

Congenital syphilis infection occur in the newborn secondary to transmission of spirochetes across the placenta during pregnancy. The risk for congenital syphilis depends on the stage of maternal infection and the stage of infection at the time of exposure during pregnancy. The infant is examined for any physical features of congenital syphilis, dark field microscopic examination is done of any suspicious lesion or body fluids, pathological examination is done of placenta or umbilical cord and infant is evaluated with standard non-treponemal serologic tests, including venereal disease research laboratory test (VDRL) or rapid plasma (RPR) test and reactive non-treponemal tests is confirmed with a treponemal-specific test. These infants need to be started on treatment with penicillin with duration and regimen of treatment depends upon the maternal treatment received, neonatal physical examination and results of neonatal serological test [207].

There is high risk of development of antibiotic resistance with the widespread use of antibiotics thus making careful and selective use of antibiotics to the highest risk patients a universal goal. Antibiotic stewardship limits the development of antimicrobial-resistant organisms and it can be done by improving use of antibiotics. Narrow spectrum antibiotics should be used, fixed protocols should be there for starting and stopping antibiotics, start antibiotic only when clinically indicated and downgrade antibiotics after seeing blood culture sensitivity pattern are few components of antibiotic stewardship [208-210].

\section{Therapeutic hypothermia for asphyxia}

Hypoxic-ischemic encephalopathy (HIE) is encephalopathy from peripartum asphyxia with incidence of moderate-to-severe HIE being 1-3 infants per 1000 atterm livebirths in developed countries and up to 20 infants per 1000 at-term livebirths in developing countries, with worse outcome seen in severe HIE when compared to moderate HIE [211]. This difference in asphyxia incidence is because of difference in level of antenatal care received by mother. Still in developing countries, deliveries take place in nonhospital settings in absence of health care personal, thus leading to high incidence of perinatal asphyxia in these countries [212]. Term and near-term newborn, having moderate or severe asphyxia should be started on therapeutic hypothermia if they fulfill the predefined criteria's of eligibilty [213, 214]. The eligibilty criteria for starting therapeutic hypothermia are a) birth weight $\geq 2000$ gram, post-menstrual age $\geq 36$ weeks, b) evidence of fetal distress or neonatal distress as evidenced by one of the following: i. history of acute perinatal event (e.g., placental abruption, cord prolapse, severe fetal heart rate abnormality); ii. $\mathrm{pH} \leq 7.0$ or base deficit $\geq 16 \mathrm{mmol} / \mathrm{L}$ in cord gas or postnatal blood gas obtained within first hour of life; iii. 10-minute Apgar score of $\leq 5$; iv. assisted ventilation initiated at birth and continued for at least 10 minutes, c) evidence of moderate to severe neonatal encephalopathy by examination and/or aEEG (amplitude integrated EEG) as follows: i. primary method for determining neonatal encephalopathy is physical exam (indicated by lethargy, stupor, or coma). ii. If exam shows moderate or severe encephalopathy, aEEG should be performed to provide further assessment and monitoring. iii. In circumstances in which physical exam is unreliable (e.g., muscle relaxants), an aEEG should be performed to determine if there is encephalopathy. iv. Patterns on aEEG that indicate moderate or severe encephalopathy includes the following, with minimum of 20 minutes recording time: a) severely abnormal: upper margin $<10 \mu \mathrm{V}$ b) moderately abnormal: upper margin $>10 \mu \mathrm{V}$ and lower margin $<5 \mu \mathrm{V}$ c) seizures identified by aEEG [215-217]. Neurological examination and Sarnath Staging of the newborn will help in assessment of severity of neonatal encephalopathy 
[218]. Electroencephalography (EEG) or aEEG have been used in classification of severity of encephalopathy, identification of seizure, see effect of anti-convulsant on seizure frequency, identification of abnormal background activity and for inclusion of starting therapeutic hypothermia [219].

Lactate is produced during anaerobic metabolism during hypoxia and poor tissue perfusion. Serum lactate has been used to as early predictor of short-term outcome after intrapartum asphyxia [220]. Shah et al. reported that initial lactate levels are significantly higher in neonates with moderate-to-severe HIE as compared to those with mild or no HIE and the lactate levels took longer to normalize in neonates with moderate to severe HIE. Thus the author concluded that highest recorded lactate level in the first hour of life and serial measurements of lactate are important predictors of moderateto-severe HIE [221]. In other study it was shown that high lactate level after 72 hours of therapeutic hypothermia is associated with poor neurodevelopmental outcome [222]. Moderate hypothermia $\left(33.5^{\circ} \mathrm{C}\right)$ for $72 \mathrm{~h}$ after birth is the only effective neural rescue therapy for infants born at term and near-term with moderate-to-severe HIE [223]. American academy of Paediatrics (AAP) recommends therapeutic hypothermia to be started within 6 hours of birth and continued for next 72 hours followed by gradual rewarming in next 6-8 hours [224]. Cochrane meta-analysis showed significant reduction in neonatal mortality and neurological impairment with the implementation of therapeutic hypothermia $[225,226]$. Therapeutic hypothermia started within one hour of post-natal life leads to reduction in incidence of clinico-electrical seizures [227]. The neonates requiring therapeutic hypothermia should be first stabilized by providing support to respiratory and cardiovascular system if required. NRP 2015 guideline recommend that in resource abundant areas newborn born at more than 36 weeks of gestation with evolving moderate-tosevere HIE should be offered therapeutic hypothermia under clearly defined protocols [213, 214]. For resource limited countries, NRP 2015 guideline states that therapeutic hypothermia may be done if the newborn fulfills predefined criteria as defined in clinical trials and in facilities with the capabilities for multidisciplinary care and longitudinal follow-up [228]. The complications of therapeutic hypothermia that are frequently seen in neonates are increase incidence of sinus bradycardia, thrombocytopenia, subcutaneous fat necrosis, hypotension, increased fibrinolytic activity, and prolongation of prothrombin time and partial thromboplastin time tests $[229,230]$. Hence goal of neonatologist in case of perinatal asphyxia is to identify the neonates fulfilling the criteria for starting therapeutic hypothermia and then starting it as early as possible, preferably in golden hour $[13,14]$.

\section{Laboratory investigation}

All the necessary investigations required for the management of newborn should be done in the golden hour so that there is minimal handling afterwards and decision is taken over the management plan. The investigations needs individualization as per the newborn clinical status and ante-natal risk factors. The list of various investigations includes complete blood count, blood culture, glucose, arterial blood gas (ABG) analysis/capillary blood gas, and chest X-ray (CXR). CXR helps in differentiating the various neonatal respiratory causes of distress. The CXR finding of RDS includes low lung volume, ground glass appearance, air bronchograms, reticulogranular pattern and white out lung [120]. The CXR features suggestive of TTN are prominent central perihilar vascular markings, edema of the interlobar septae, fluid in the interlobar fissures, mild cardiomegaly, minimal pleural effusion, and hyperinflation [121]. In pulmonary hypoplasia CXR will be suggestive of low lung volume on the affected side with mediastinal shift to the same side [231]. The X-ray feature suggestive of air leak syndrome will be leakage of air from the alveoli into the extra-alveolar space like pneumothorax (air collection in pleural space), pneumomediastinum (collection of air in mediastinum), pneumopericardium (collection of air around heart in pericardium), and pulmonary interstitial emphysema (PIE) (presence of air in the lung interstitium) [232-234]. CXR in meconium aspiration syndrome typically shows diffuse, asymmetric patchy infiltrates, areas of consolidation, often worse on the right, hyperinflation and sometimes presence of air leak syndrome [235]. In case of perinatal asphyxia cord blood ABG or ABG within first hour will help us decide about starting of therapeutic hypothermia. In case of immune hydrops fetalis, necessary investigations required are total serum bilirubin, direct coombs test, reticulocyte count, and hematocrit for guiding about need for partial exchange or double volume exchange transfusion (DVET) and phototherapy. Partial exchange transfusion is indicated prior to DVET when the newborn is hydropic or anemic (hematocrit <30\%) [236]. Similarly CXR in case of congenital diaphragmatic hernia will tell us about the severity of lung compromise and will help us in prognostication of neonate [237].

\section{Monitoring/Record}

Monitoring and record keeping is an important part of golden hour. All the vital parameters of the newborn like heart rate, respiratory rate, capillary refill time, invasive or non-invasive blood pressure, saturation, and blood sugar should be monitored and recorded in the newborn case record. Near infrared spectroscopy (NIRS) is newly emerging technology in which bed side assessment is done of tissue blood flow/perfusion including cerebral, 
renal, and gastro-intestinal tract in neonates having perinatal asphyxia, shock, cyanotic heart disease or intestinal surgeries [238-240]. NIRS has been used in management of neonates undergoing surgical correction for complex congenital heart disease. The studies shows that low cerebral regional oxygen saturation (cRSO2) correlate with poorer neurologic outcomes and increased perioperative mortality. Interventions need to be done to increase cRSO2 if there is decrease in it by $\geq 20 \%$ from a stable baseline [241]. NIRS has been used for monitoring cRSO2 in neonates during transition after birth, a period when the brain is vulnerable to injury and dysfunction [242]. It has also been used in premature newborn to see the impact of prematurity and intensive care on early brain development [243]. The other clinical usage of NIRS includes cerebral oxygenation assessment in HIE, preterm neonates with hypotension, preterm neonates with patent ductus arteriosus (PDA), preterm neonates with respiratory distress syndrome (RDS), neonates with peri/intraventricular hemorrhage $(\mathrm{P} / \mathrm{IVH})$ and preterm neonate with apneas and bradycardias [241]. Record needs to be kept of the various intervention done with their timing as this will guide us about the scope of any improvement in the aspect of timing of various interventions in the golden hour. The records keeping includes Apgar score, interventions done during resuscitation, birth weight, axillary temperature at time of admission to nursery, time of surfactant instillation, time of umbilical catheterization, time of starting ventilation and CPAP, time of starting therapeutic hypothermia, time of giving first feeds, time of starting intravenous fluids and TPN, time of giving first dose of antibiotics, complications secondary to any neonatal procedure, size and depth of endotracheal tube, umbilical catheters and depth of feeding tube fixation $[1,237]$.

\section{Communication and counselling of family}

This is an important aspect of golden hour and includes talking with parents and relatives of newborn for updating about the postnatal condition of newborn. The parents of term stable newborn, shifted to mother should be counselled regarding maintenance of temperature, frequency of breast feeding with emphasis on starting of early feeding and maintenance of asepsis in the newborn care. The parents of preterm and term newborns admitted in nursery or requiring referral to higher center, should be counselled regarding the present status, interventions that have been done till that time and further plan of management. All the questions of the parents should be answered patiently and counselling should be documented and all necessary consent should be taken from the parents like admission, procedure, transportation, and starting of hypothermia consents. The obstetrician who was involved in the antenatal care of the newborn should also be informed about the condition and plan of management [237]. Post-counselling documentation should be done and is important in providing a record to which future health-care professionals can refer like starting point for later discussions or usage as a form of legal document if advance treatment preferences are being decided [244].

\section{Transportation in Golden Hour}

The infant may sometimes need transportation to health care center just after birth either because of lack of facilities for the neonatal care to the place neonate is born or because of home delivery to provide specific neonatal care. The aim of neonatal transport is to transfer a newborn infant requiring intensive care to a center where specialized resources and experience can be provided for the appropriate assessment and continuing treatment of a sick newborn infant [245]. These VLBW, ELBW, EGLAN and sometimes term neonates require transfer to tertiary centers for management and often hypothermic on reaching referral center due to lack of adequate precautions for hypothermia prevention during transport [246, 247]. In Golden hour, the neonate should be first stabilized and during transportation care should be taken for maintenance of temperature, sugar and necessary interventions need to be done for supporting heart, lungs and brain like giving ventilatory/CPAP support if required and starting of inotropes if the newborn is in shock. The infant should be started on intravenous fluids if shifting to tertiary health care center and referred hospital should be informed regarding this transport so that the neonate receives required care on reaching the center [248].

\section{Current evidence for golden hour}

The current evidence that sought the effect of golden hour in care of VLBW/ ELBW reported increase in admission temperature after implementation of golden hour project $[1,249]$, increase in number of infants with an admission temperature of $36.5{ }^{\circ} \mathrm{C}-37.4{ }^{\circ} \mathrm{C}$ [250], decrease in the incidence of ROP and BPD [1, 249], significant improvement in time of surfactant administration, time to start dextrose and amino acids infusion $[7,249,250]$, significant decrease in time to give antibiotics [7], decrease in the incidence of IVH, faster placement of umbilical catheters, significant reduction in time to reach in the NICU after delivery [251], incidence of admission glucose greater than 50 $\mathrm{mg} / \mathrm{dL}$ [133]. Presently, there are no studies that have sought the role of golden hour in term neonates. We purpose flow diagram for the care of preterm and term newborn during the critical golden hour that will be helpful for management of these newborns (Fig. 2). 


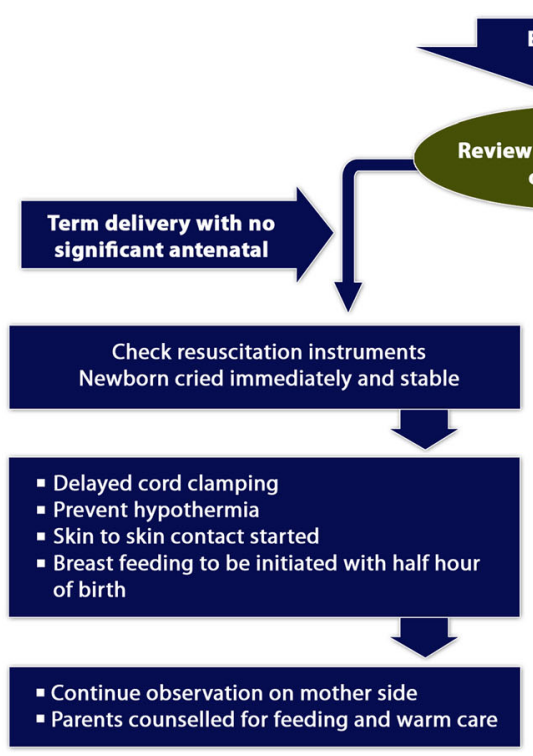

Nursery team to be informed

- Obstetrician to discussed about the plan of

management, indication of preterm delivery and

condition of fetus

- Parents to be counselled regarding management and need for admission

- Role and responsibility allotted to members of resuscitation team

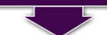

Resuscitation preparation

- Use radiant warmer/polyethylene wrap/vinyl

bag/thermal mattress

- T piece resuscitator with blender/CPAP

- Massimo pulse oximeter, humidifier

- Delivery room/ OT temp. $26-28^{\circ} \mathrm{C}$

- Umbilical catheter, IV cannula

- Pre-warmed transport incubator

Newborn required resuscitation/need for admission
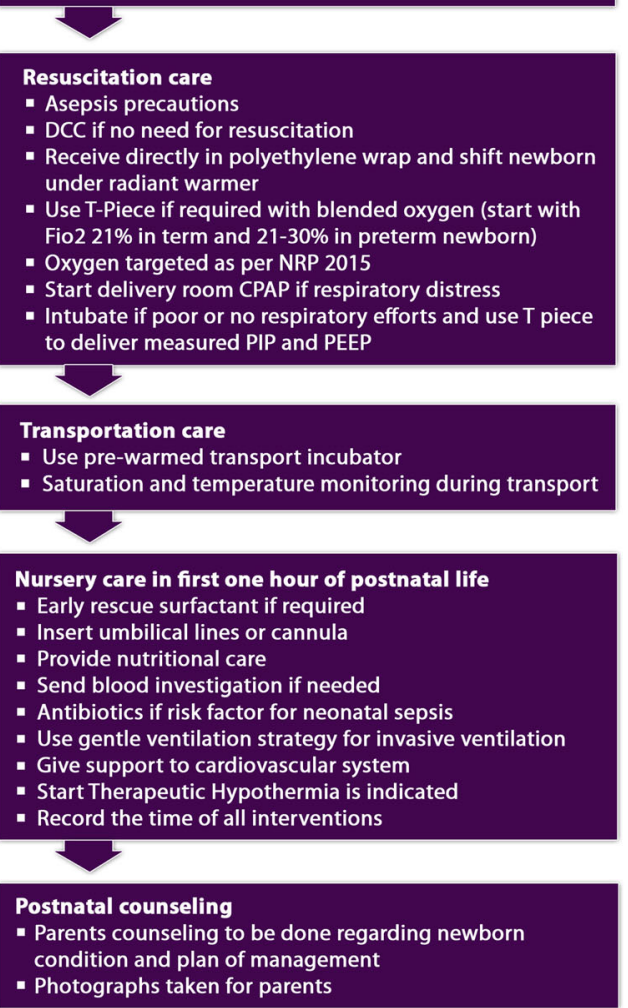

Fig. 2 Figure showing proposed algorithm of preterm and term newborn care during golden 60 minutes of life. (Figure copyright Dr Deepak Sharma)

\section{Conclusion}

The concept of "Golden hour" is new evolving strategy for better outcome of preterm and term neonates. All the health care personal should be explained about the components and importance of golden hour approach. Neonatologist attending the birth of VLBW/ELBW/ ELGAN or high-risk term neonate should be well trained in attending such deliveries and should implement all the 
components of golden hour during the initial first hour of post-natal life. Predelivery checklist should be followed and implemented, with teaching of the health care personal should be continuous for implementation of golden hour. The various components of golden hour include ante-natal counseling and team briefing, delayed cord clamping, prevention of hypothermia, support to respiratory and cardiovascular system, nutritional support, prevention of sepsis, therapeutic hypothermia, laboratory investigation, record keeping and counselling of parents. The current evidence supports the use of Golden hour concept by showing reduction in various neonatal morbidities like hypothermia, ROP and BPD thus showing positive impact over the survival and morbidity of the preterm and high risk term infants.

\begin{abstract}
Abbreviations
AAP: American academy of Paediatrics; ABG: Arterial blood gas; ARV: Antiretroviral; BHFI: Baby Friendly Hospital Initiative; BP: Blood Pressure; BPD: Bronchopulmonary dysplasia; CHAOS: Congenital high airway obstruction; Cl: Confidence interval; CNS: Central nervous system; CPAP: Continuous positive airway pressure; CSF: Cerebrospinal fluid CXR: Chest X-ray; DCC: Delayed cord clamping; DVET: Double volume exchange transfusion; ECC: Early cord clamping; ECMO: Extracorporea membrane oxygenation; ELBW: Extremely low birth weight; ELGAN: Extremely low gestational age neonates; EOS: Early onset sepsis; FE: Functional echocardiography; FRC: Functional residual capacity; GBS: Group B Streptococci; GIR: Glucose infusion rate; HIE: Hypoxic-ischemic encephalopathy; HSV: Herpes simplex virus; IV: Intravenous; IVH: Intraventricular hemorrhage; NEC: Necrotizing enterocolitis; NICU: Neonatal intensive care unit; NIMV: Non-invasive mechanical ventilation; NIRS: Near infrared spectroscopy; NRP: Neonatal resuscitation programme; PDA: Patent ductus arteriosus; PEEP: Peak end expiratory pressure; PFO: Patent Foramen Ovale; PIE: Pulmonary interstitial emphysema; PIP: Peak inspiratory pressure; PPHN: Persistent Pulmonary Hypertension; PPV: Positive pressure ventilation; RDS: Respiratory distress syndrome; ROP: Retinopathy of prematurity; RPR: Rapid plasma test; RR: Relative risk; SEM: Skin, eye and mucocutaneous; SLI: Sustained lung inflation; SSC: Skin-to-skin care; SVC: Superior vena cava flow; TIPP: Trial of Indomethacin prophylaxis in preterms; TPN: Total parenteral nutrition; UCM: Umbilical cord milking; VDRL: Venereal disease research laboratory test; VLBW: Very low birth weight
\end{abstract}

\section{Acknowledgements \\ None}

\section{Funding}

No external funding for this manuscript

Availability of data and materials

Not applicable as this a review article.

\section{Financial disclosure}

None

\section{Authors' contributions}

DS made substantial contribution to conception and design of the case report. DS involved in drafting the manuscript or revising it critically for important intellectual content. DS gave final approval of the version to be published. DS agreed to be accountable for all aspects of the work in ensuring that questions related to the accuracy or integrity of any part of the work are appropriately investigated and resolved.

Ethics approval and consent to participate

Not applicable as this is review article.
Consent for publication

Not applicable as this is review article.

Competing interests

The authors declared that they have no competing interests.

\section{Publisher's Note}

Springer Nature remains neutral with regard to jurisdictional claims in published maps and institutional affiliations.

Received: 22 May 2017 Accepted: 31 August 2017

Published online: 19 September 2017

References

1. Reynolds RD, Pilcher J, Ring A, Johnson R, McKinley P. The Golden Hour: care of the LBW infant during the first hour of life one unit's experience. Neonatal Netw NN. 2009 Aug;28(4):211-219; quiz 255-258.

2. Lerner EB, Moscati RM. The golden hour: scientific fact or medical "urban legend"? Acad Emerg Med Off J Soc Acad Emerg Med. 2001 Jul;8(7):758-60.

3. Sasada M, Williamson K, Gabbott D. The golden hour and pre-hospital trauma care. Injury. 1995 Apr;26(3):215-6.

4. Cowley RA, Hudson F, Scanlan E, Gill W, Lally RJ, Long W, et al. An economical and proved helicopter program for transporting the emergency critically ill and injured patient in Maryland. J Trauma. 1973 Dec;13(12):1029-38.

5. Wyckoff MH. Initial resuscitation and stabilization of the periviable neonate: the Golden-Hour approach. Semin Perinatol. 2014 Feb;38(1):12-6.

6. Vento M, Cheung P-Y, Aguar M. The first golden minutes of the extremelylow-gestational-age neonate: a gentle approach. Neonatology. 2009;95(4):286-98.

7. Lambeth TM, Rojas MA, Holmes AP. Dail RB. A Quality Improvement Initiative. Adv Neonatal Care Off J Natl Assoc Neonatal Nurses: First Golden Hour of Life; 2016 Jul 7.

8. Sharma D. Golden 60 minutes of newborn's life: Part 1: Preterm neonate. J Matern-Fetal Neonatal Med Off J Eur Assoc Perinat Med Fed Asia Ocean Perinat Soc Int Soc Perinat Obstet. 2016 Dec;1:1-12.

9. Sharma D, Sharma P, Shastri S. Golden 60 minutes of newborn's life: Part 2: Term neonate. J Matern-Fetal Neonatal Med Off J Eur Assoc Perinat Med Fed Asia Ocean Perinat Soc Int Soc Perinat Obstet. 2016 Nov;29:1-6.

10. Hoekstra RE, Ferrara TB, Couser RJ, Payne NR, Connett JE. Survival and long-term neurodevelopmental outcome of extremely premature infants born at 23-26 weeks' gestational age at a tertiary center. Pediatrics. 2004 Jan;113(1 Pt 1):e1-6.

11. Hintz SR, Kendrick DE, Vohr BR, Poole WK, Higgins RD. National Institute of Child Health and Human Development Neonatal Research Network. Changes in neurodevelopmental outcomes at 18 to 22 months' corrected age among infants of less than 25 weeks' gestational age born in 19931999. Pediatrics. 2005 Jun;115(6):1645-51.

12. Hack M, Taylor HG, Drotar D, Schluchter M, Cartar L, Andreias L, et al. Chronic conditions, functional limitations, and special health care needs of school-aged children born with extremely low-birth-weight in the 1990s. JAMA. 2005 Jul 20;294(3):318-25.

13. Wyckoff MH, Aziz K, Escobedo MB, Kapadia VS, Kattwinkel J, Perlman JM, et al. Part 13: Neonatal Resuscitation: 2015 American Heart Association Guidelines Update for Cardiopulmonary Resuscitation and Emergency Cardiovascular Care. Circulation. 2015 Nov 3;132(18 Suppl 2):S543-60.

14. Wyckoff MH, Aziz K, Escobedo MB, Kapadia VS, Kattwinkel J, Perlman JM, et al. Part 13: Neonatal Resuscitation: 2015 American Heart Association Guidelines Update for Cardiopulmonary Resuscitation and Emergency Cardiovascular Care (Reprint). Pediatrics. 2015 Nov;136(Suppl 2):S196-218.

15. Smith PB, Ambalavanan N, Li L, Cotten CM, Laughon M, Walsh MC, et al. Approach to Infants Born at 22 to 24 Weeks' Gestation: Relationship to Outcomes of More-Mature Infants. Pediatrics. 2012 Jun;129(6):e1508-16.

16. Brett J, Staniszewska S, Newburn M, Jones N, Taylor L. A systematic mapping review of effective interventions for communicating with, supporting and providing information to parents of preterm infants. BMJ Open. 2011 Jun 2;1(1):e000023.

17. Cummings J, COMMITTEE ON FETUS AND NEWBORN. Antenatal Counseling Regarding Resuscitation and Intensive Care Before 25 Weeks of Gestation. Pediatrics. 2015 Sep;136(3):588-595. 
18. Watts $J$, Saigal S. Outcome of extreme prematurity: as information increases so do the dilemmas. Arch Dis Child Fetal Neonatal Ed. 2006 May;91(3):F221-5.

19. Tyson JE, Parikh NA, Langer J, Green C, Higgins RD. National Institute of Child Health and Human Development Neonatal Research Network. Intensive care for extreme prematurity-moving beyond gestational age. N Engl J Med. 2008 Apr 17;358(16):1672-81.

20. Ambalavanan N, Baibergenova A, Carlo WA, Saigal S, Schmidt B, Thorpe KE, et al. Early prediction of poor outcome in extremely low birth weight infants by classification tree analysis. J Pediatr. 2006 Apr;148(4):438-44

21. Singh J, Fanaroff J, Andrews B, Caldarelli L, Lagatta J, Plesha-Troyke S, et al. Resuscitation in the "gray zone" of viability: determining physician preferences and predicting infant outcomes. Pediatrics. 2007 Sep;120(3):519-26.

22. Batton DG. Committee on Fetus and Newborn. Clinical report-Antenatal counseling regarding resuscitation at an extremely low gestational age. Pediatrics. 2009 Jul;124(1):422-7.

23. Kaempf JW, Tomlinson MW, Campbell B, Ferguson L, Stewart VT. Counseling pregnant women who may deliver extremely premature infants: medical care guidelines, family choices, and neonatal outcomes. Pediatrics. 2009 Jun;123(6):1509-15.

24. Chandrasekharan PK, Rawat M, Madappa R, Rothstein DH, Lakshminrusimha S. Congenital Diaphragmatic hernia - a review. Matern Health Neonatol Perinatol. 2017;3:6

25. Lakhoo K. Fetal counselling for surgical conditions. Early Hum Dev. 2012 Jan;88(1):9-13.

26. Wyllie J, Perlman JM, Kattwinkel J, Atkins DL, Chameides L, Goldsmith JP, et al. Part 11: Neonatal resuscitation: 2010 International Consensus on Cardiopulmonary Resuscitation and Emergency Cardiovascular Care Science with Treatment Recommendations. Resuscitation. 2010 Oct;81(Suppl 1):e260-87.

27. Perlman JM, Wyllie J, Kattwinkel J, Atkins DL, Chameides L, Goldsmith JP, et al. Part 11: Neonatal resuscitation: 2010 International Consensus on Cardiopulmonary Resuscitation and Emergency Cardiovascular Care Science With Treatment Recommendations. Circulation. 2010 Oct 19;122(16 Suppl 2):S516-38.

28. Jelin AC, Zlatnik MG, Kuppermann M, Gregorich SE, Nakagawa S, Clyman R. Clamp late and maintain perfusion (CLAMP) policy: delayed cord clamping in preterm infants. J Matern-Fetal Neonatal Med Off J Eur Assoc Perinat Med Fed Asia Ocean Perinat Soc Int Soc Perinat Obstet. 2016 Jun;29(11):1705-9.

29. Arca G, Botet F, Palacio M, Carbonell-Estrany X. Timing of umbilical cord clamping: new thoughts on an old discussion. J Matern-Fetal Neonatal Med Off J Eur Assoc Perinat Med Fed Asia Ocean Perinat Soc Int Soc Perinat Obstet. 2010 Nov:23(11):1274-85.

30. Raju TNK, Singhal N. Optimal timing for clamping the umbilical cord after birth. Clin Perinatol. 2012 Dec;39(4):889-900.

31. Duley L, Batey N. Optimal timing of umbilical cord clamping for term and preterm babies. Early Hum Dev. 2013 Nov;89(11):905-8.

32. Raju TNK. Timing of umbilical cord clamping after birth for optimizing placental transfusion. Curr Opin Pediatr. 2013 Apr:25(2):180-7.

33. Backes CH, Rivera B, Haque U, Copeland K, Hutchon D, Smith CV. Placental transfusion strategies in extremely preterm infants: the next piece of the puzzle. J Neonatal Perinatal Med. 2014;7(4):257-67. doi:10.3233/NPM14814034. Review. PubMed PMID: 25468622.

34. Kim AJH, Warren JB. Optimal Timing of Umbilical Cord Clamping: Is the Debate Settled? Part 1 of 2: History, Rationale, Influencing Factors, and Concerns. NeoReviews. 2015 May 1;16(5):e263-9.

35. Kim AJH, Warren JB. Optimal Timing of Umbilical Cord Clamping: Is the Debate Settled? Part 2 of 2: Evidence in Preterm and Term Infants, Alternatives, and Unanswered Questions. NeoReviews. 2015 May 1;16(5):e270-7.

36. Eichenbaum-Pikser G, Zasloff JS. Delayed clamping of the umbilical cord: a review with implications for practice. J Midwifery Womens Health. 2009 Aug;54(4):321-6.

37. Katheria AC, Lakshminrusimha S, Rabe H, McAdams R, Mercer JS. Placental transfusion: a review. J Perinatol Off J Calif Perinat Assoc. 2017 Feb;37(2):105-11.

38. Farrar D, Airey R, Law GR, Tuffnell D, Cattle B, Duley L. Measuring placental transfusion for term births: weighing babies with cord intact. BJOG Int J Obstet Gynaecol. 2011 Jan;118(1):70-5.
39. Katheria AC, Brown MK, Rich W, Arnell K. Providing a Placental Transfusion in Newborns Who Need Resuscitation. Front Pediatr. 2017;5:1.

40. Rabe H, Diaz-Rossello JL, Duley L, Dowswell T. Effect of timing of umbilical cord clamping and other strategies to influence placental transfusion at preterm birth on maternal and infant outcomes. Cochrane Database Syst Rev. 2012;8:CD003248.

41. McDonald SJ, Middleton P, Dowswell T, Morris PS. Effect of timing of umbilical cord clamping of term infants on maternal and neonatal outcomes. Cochrane Database Syst Rev. 2013;7:CD004074.

42. Niermeyer S. A physiologic approach to cord clamping: Clinical issues. Matern Health Neonatol Perinatol. 2015:1:21.

43. Rabe H, Jewison A, Alvarez RF, Crook D, Stilton D, Bradley R, et al. Milking compared with delayed cord clamping to increase placental transfusion in preterm neonates: a randomized controlled trial. Obstet Gynecol. 2011 Feb;117(2 Pt 1):205-11.

44. Hosono S, Mugishima H, Fujita H, Hosono A, Minato M, Okada T, et al Umbilical cord milking reduces the need for red cell transfusions and improves neonatal adaptation in infants born at less than 29 weeks' gestation: a randomised controlled trial. Arch Dis Child Fetal Neonatal Ed. 2008 Jan;93(1):F14-9.

45. Upadhyay A, Gothwal S, Parihar R, Garg A, Gupta A, Chawla D, et al. Effect of umbilical cord milking in term and near term infants: randomized control trial. Am J Obstet Gynecol. 2013 Feb;208(2):120.e1-6.

46. Laptook AR, Salhab W, Bhaskar B. Neonatal Research Network. Admission temperature of low birth weight infants: predictors and associated morbidities. Pediatrics. 2007 Mar;119(3):e643-9.

47. Costeloe K, Hennessy E, Gibson AT, Marlow N, Wilkinson AR. The EPICure study: outcomes to discharge from hospital for infants born at the threshold of viability. Pediatrics. 2000 Oct;106(4):659-71.

48. Bhatt DR, White R, Martin G, Van Marter LJ, Finer N, Goldsmith JP, et al. Transitional hypothermia in preterm newborns. J Perinatol Off J Calif Perinat Assoc. 2007 Dec;27(Suppl 2):S45-7.

49. Boo N-Y, Guat-Sim Cheah I. Malaysian National Neonatal Registry. Admission hypothermia among VLBW infants in Malaysian NICUs. J Trop Pediatr. 2013 Dec;59(6):447-52

50. Chang $\mathrm{H}-\mathrm{Y}$, Sung $\mathrm{Y}-\mathrm{H}$, Wang $\mathrm{S}-\mathrm{M}$, Lung $\mathrm{H}-\mathrm{L}$, Chang J-H, Hsu C-H, et al. Short- and Long-Term Outcomes in Very Low Birth Weight Infants with Admission Hypothermia. PloS One. 2015;10(7):e0131976.

51. Mathur NB, Krishnamurthy S, Mishra TK. Evaluation of WHO classification of hypothermia in sick extramural neonates as predictor of fatality. J Trop Pediatr. 2005 Dec;51(6):341-5.

52. Raman S, Shahla A. Temperature drop in normal term newborn infants born at the University Hospital, Kuala Lumpur. Aust N Z J Obstet Gynaecol. 1992 May;32(2):117-9.

53. Watkinson M. Temperature control of premature infants in the delivery room. Clin Perinatol. 2006 Mar;33(1):43-53, vi.

54. Szymankiewicz M. Thermoregulation and maintenance of appropriate temperature in newborns. Ginekol Pol. 2003 Nov;74(11):1487-97.

55. Belsches TC, Tilly AE, Miller TR, Kambeyanda RH, Leadford A, Manasyan A, et al. Randomized trial of plastic bags to prevent term neonatal hypothermia in a resource-poor setting. Pediatrics. 2013 Sep;132(3):e656-61.

56. Oatley HK, Blencowe H, Lawn JE. The effect of coverings, including plastic bags and wraps, on mortality and morbidity in preterm and full-term neonates. J Perinatol. 2016 May;36(S1):S83-9.

57. L'Herault J, Petroff $L$, Jeffrey J. The effectiveness of a thermal mattress in stabilizing and maintaining body temperature during the transport of very low-birth weight newborns. Appl Nurs Res ANR. 2001 Nov;14(4):210-9.

58. Mathew B, Lakshminrusimha S, Sengupta S, Carrion V. Randomized controlled trial of vinyl bags versus thermal mattress to prevent hypothermia in extremely low-gestational-age infants. Am J Perinatol. 2013 Apr;30(4):317-22.

59. Laptook AR, Watkinson M. Temperature management in the delivery room. Semin Fetal Neonatal Med. 2008 Dec;13(6):383-91.

60. Meyer MP, Hou D, Ishrar NN, Dito I, te Pas AB. Initial respiratory support with cold, dry gas versus heated humidified gas and admission temperature of preterm infants. J Pediatr. 2015 Feb;166(2):245-250.e1.

61. te Pas AB, Lopriore E, Dito I, Morley CJ, Walther FJ. Humidified and heated air during stabilization at birth improves temperature in preterm infants. Pediatrics. 2010 Jun;125(6):e1427-32.

62. Marín Gabriel MA, Llana Martín I, López Escobar A, Fernández Villalba E Romero Blanco I, Touza Pol P. Randomized controlled trial of early skin-to- 
skin contact: effects on the mother and the newborn. Acta Paediatr Oslo Nor 1992. 2010 Nov;99(11):1630-4.

63. Bergman NJ, Linley LL, Fawcus SR. Randomized controlled trial of skin-toskin contact from birth versus conventional incubator for physiological stabilization in 1200- to 2199-gram newborns. Acta Paediatr Oslo Nor 1992. 2004 Jun;93(6):779-85.

64. Lenclen R, Mazraani M, Jugie M, Couderc S, Hoenn E, Carbajal R, et al. Use of a polyethylene bag: a way to improve the thermal environment of the premature newborn at the delivery room. Arch Pédiatrie Organe Off Sociéte Fr Pédiatrie. 2002 Mar;9(3):238-44.

65. Doglioni N, Cavallin F, Mardegan V, Palatron S, Filippone M, Vecchiato L, et al. Total body polyethylene wraps for preventing hypothermia in preterm infants: a randomized trial. J Pediatr. 2014 Aug;165(2):261-266.e1.

66. Leadford AE, Warren JB, Manasyan A, Chomba E, Salas AA, Schelonka R, et al. Plastic bags for prevention of hypothermia in preterm and low birth weight infants. Pediatrics. 2013 Jul;132(1):e128-34.

67. Chantaroj S, Techasatid W. Effect of polyethylene bag to prevent heat loss in preterm infants at birth: a randomized controlled trial. J Med Assoc Thail Chotmaihet Thangphaet. 2011 Dec;94(Suppl 7):S32-7.

68. Trevisanuto D, Doglioni N, Cavallin F, Parotto M, Micaglio M, Zanardo V. Heat loss prevention in very preterm infants in delivery rooms: a prospective, randomized, controlled trial of polyethylene caps. J Pediatr. 2010 Jun;156(6):914-917, 917.e1.

69. Vohra S, Roberts RS, Zhang B, Janes M, Schmidt B. Heat Loss Prevention (HeLP) in the delivery room: A randomized controlled trial of polyethylene occlusive skin wrapping in very preterm infants. J Pediatr. 2004 Dec;145(6):750-3.

70. Vohra S, Frent G, Campbell V, Abbott M, Whyte R. Effect of polyethylene occlusive skin wrapping on heat loss in very low birth weight infants at delivery: a randomized trial. J Pediatr. 1999 May;134(5):547-51.

71. Yeh TF, Voora S, Lilien LD, Matwynshyn J, Srinivasan G, Pildes RS. Oxygen consumption and insensible water loss in premature infants in single-versus double-walled incubators. J Pediatr. 1980 Dec;97(6):967-71.

72. Bansal SC, Nimbalkar SM. Updated Neonatal Resuscitation Guidelines 2015 Major Changes. Indian Pediatr. 2016 May 8;53(5):403-8.

73. McCall EM, Alderdice F, Halliday HL, Jenkins JG, Vohra S. Interventions to prevent hypothermia at birth in preterm and/or low birthweight infants. Cochrane Database Syst Rev. 2010;3:CD004210.

74. Sweet DG, Carnielli V, Greisen G, Hallman M, Ozek E, Plavka R, et al. European consensus guidelines on the management of neonatal respiratory distress syndrome in preterm infants-2013 update. Neonatology. 2013; 103(4):353-68

75. Sweet DG, Carnielli V, Greisen G, Hallman M, Ozek E, Plavka R, et al. European Consensus Guidelines on the Management of Respiratory Distress Syndrome - 2016 Update. Neonatology. 2017;111(2):107-25.

76. Deschmann E, Norman M. Oxygen-saturation targets in extremely preterm infants. Acta Paediatr Oslo Nor 1992. 2017 Jun;106(6):1014.

77. Polin RA, Bateman D. Oxygen-saturation targets in preterm infants. N Engl J Med. 2013 May 30;368(22):2141-2.

78. Kattwinkel J, Perlman JM, Aziz K, Colby C, Fairchild K, Gallagher J, et al. Part 15: neonatal resuscitation: 2010 American Heart Association Guidelines for Cardiopulmonary Resuscitation and Emergency Cardiovascular Care. Circulation. 2010 Nov 2;122(18 Suppl 3):S909-19.

79. Kattwinkel J, Perlman JM, Aziz K, Colby C, Fairchild K, Gallagher J, et al. Neonatal resuscitation: 2010 American Heart Association Guidelines for Cardiopulmonary Resuscitation and Emergency Cardiovascular Care. Pediatrics. 2010 Nov;126(5):e1400-13.

80. DeBoer S, Seaver M. End-tidal CO2 verification of endotracheal tube placement in neonates. Neonatal Netw NN. 2004 Jun;23(3):29-38.

81. Sly PD, Drew JH. Air leak in neonatal respiratory distress syndrome. Anaesth Intensive Care. 1984 Feb;12(1):41-5.

82. Lindner W, Högel J, Pohlandt F. Sustained pressure-controlled inflation or intermittent mandatory ventilation in preterm infants in the delivery room? A randomized, controlled trial on initial respiratory support via nasopharyngeal tube. Acta Paediatr Oslo Nor 1992. 2005 Mar;94(3):303-9.

83. te Pas $A B$, Walther FJ. A randomized, controlled trial of delivery-room respiratory management in very preterm infants. Pediatrics. 2007 Aug;120(2):322-9.

84. Harling AE, Beresford MW, Vince GS, Bates M, Yoxall CW. Does sustained lung inflation at resuscitation reduce lung injury in the preterm infant? Arch Dis Child Fetal Neonatal Ed. 2005 Sep;90(5):F406-10.
85. Lista G, Boni L, Scopesi F, Mosca F, Trevisanuto D, Messner H, et al. Sustained lung inflation at birth for preterm infants: a randomized clinical trial. Pediatrics. 2015 Feb;135(2):e457-64.

86. Vali P, Mathew B, Lakshminrusimha S. Neonatal resuscitation: evolving strategies. Matern Health Neonatol Perinatol. 2015 Jan;1

87. Morley CJ, Davis PG, Doyle LW, Brion LP, Hascoet J-M, Carlin JB, et al. Nasal CPAP or intubation at birth for very preterm infants. N Engl J Med. 2008 Feb 14;358(7):700-8.

88. SUPPORT Study Group of the Eunice Kennedy Shriver NICHD Neonatal Research Network, Finer NN, Carlo WA, Walsh MC, Rich W, Gantz MG, et al. Early CPAP versus surfactant in extremely preterm infants. N Engl J Med. 2010 May 27;362(21):1970-9.

89. Rojas MA, Lozano JM, Rojas MX, Laughon M, Bose CL, Rondon MA, et al. Very early surfactant without mandatory ventilation in premature infants treated with early continuous positive airway pressure: a randomized, controlled trial. Pediatrics. 2009 Jan;123(1):137-42.

90. Kandraju H, Murki S, Subramanian S, Gaddam P, Deorari A, Kumar P. Early routine versus late selective surfactant in preterm neonates with respiratory distress syndrome on nasal continuous positive airway pressure: a randomized controlled trial. Neonatology. 2013;103(2):148-54.

91. Rojas-Reyes MX, Morley CJ, Soll R. Prophylactic versus selective use of surfactant in preventing morbidity and mortality in preterm infants. Cochrane Database Syst Rev. 2012;3:CD000510.

92. Morley CJ. Volume-limited and volume-targeted ventilation. Clin Perinatol. 2012 Sep;39(3):513-23.

93. Miller JD, Carlo WA. Safety and effectiveness of permissive hypercapnia in the preterm infant. Curr Opin Pediatr. 2007 Apr;19(2):142-4.

94. Ryu J, Haddad G, Carlo WA. Clinical effectiveness and safety of permissive hypercapnia. Clin Perinatol. 2012 Sep;39(3):603-12.

95. Davis PG, Morley CJ, Owen LS. Non-invasive respiratory support of preterm neonates with respiratory distress: continuous positive airway pressure and nasal intermittent positive pressure ventilation. Semin Fetal Neonatal Med. 2009 Feb;14(1):14-20.

96. Thome UH, Ambalavanan N. Permissive hypercapnia to decrease lung injury in ventilated preterm neonates. Semin Fetal Neonatal Med. 2009 Feb;14(1):21-7.

97. Hummler $\mathrm{H}$, Schulze A. New and alternative modes of mechanical ventilation in neonates. Semin Fetal Neonatal Med. 2009 Feb;14(1):42-8.

98. Guven S, Bozdag S, Saner H, Cetinkaya M, Yazar AS, Erguven M. Early neonatal outcomes of volume guaranteed ventilation in preterm infants with respiratory distress syndrome. J Matern Fetal Neonatal Med. 2013 Mar 1;26(4):396-401.

99. Özkan H, Duman N, Kumral A, Gülcan H. Synchronized ventilation of verylow-birth-weight infants; report of 6 years' experience. J Matern Fetal Neonatal Med. 2004 Apr 1;15(4):261-5.

100. Dani C, Lista G, Pratesi S, Boni L, Agosti M, Biban P, et al. Sustained lung inflation in the delivery room in preterm infants at high risk of respiratory distress syndrome (SLI STUDY): study protocol for a randomized controlled trial. Trials. 2013;14:67.

101. Lista G, Fontana P, Castoldi F, Cavigioli F, Dani C. Does sustained lung inflation at birth improve outcome of preterm infants at risk for respiratory distress syndrome? Neonatology. 2011;99(1):45-50.

102. Richmond S, Wyllie J. European Resuscitation Council Guidelines for Resuscitation 2010 Section 7. Resuscitation of babies at birth. Resuscitation. 2010 Oct:81(10):1389-99.

103. Rawat M, Chandrasekharan PK, Williams A, Gugino S, Koenigsknecht C, Swartz $D$, et al. Oxygen saturation index and severity of hypoxic respiratory failure. Neonatology. 2015;107(3):161-6.

104. Thomas NJ, Shaffer ML, Willson DF, Shih M-C, Curley MAQ. Defining acute lung disease in children with the oxygenation saturation index. Pediatr Crit Care Med J Soc Crit Care Med World Fed Pediatr Intensive Crit Care Soc. 2010 Jan;11(1):12-7.

105. Leone TA, Finer NN, Rich W. Delivery room respiratory management of the term and preterm infant. Clin Perinatol. 2012 Sep;39(3):431-40.

106. Wheeler K, Klingenberg C, McCallion N, Morley CJ, Davis PG. Volumetargeted versus pressure-limited ventilation in the neonate. Cochrane Database Syst Rev. 2010 Nov 10;11:CD003666.

107. Lemyre B, Laughon M, Bose C, Davis PG. Early nasal intermittent positive pressure ventilation (NIPPV) versus early nasal continuous positive airway pressure (NCPAP) for preterm infants. Cochrane Database Syst Rev. 2016 15;12:CD005384 
108. Lemyre B, Davis PG, De Paoli AG, Kirpalani H. Nasal intermittent positive pressure ventilation (NIPPV) versus nasal continuous positive airway pressure (NCPAP) for preterm neonates after extubation. Cochrane Database Syst Rev. 2017 01:2:CD003212.

109. Jobe AH, Bancalari E. Bronchopulmonary dysplasia. Am J Respir Crit Care Med. 2001 Jun;163(7):1723-9.

110. Ardell S, Pfister RH, Soll R. Animal derived surfactant extract versus protein free synthetic surfactant for the prevention and treatment of respiratory distress syndrome. Cochrane Database Syst Rev. 2015 Aug 24;8:CD000144

111. Pfister RH, Soll RF, Wiswell T. Protein containing synthetic surfactant versus animal derived surfactant extract for the prevention and treatment of respiratory distress syndrome. Cochrane Database Syst Rev. 2007 Oct 17:4:CD006069.

112. Bahadue FL, Soll R. Early versus delayed selective surfactant treatment for neonatal respiratory distress syndrome. Cochrane Database Syst Rev. 2012 Nov 14;11:CD001456.

113. Dani C, Corsini I, Bertini G, Fontanelli G, Pratesi S, Rubaltelli FF. The INSURE method in preterm infants of less than 30 weeks' gestation. J Matern-Fetal Neonatal Med Off J Eur Assoc Perinat Med Fed Asia Ocean Perinat Soc Int Soc Perinat Obstet. 2010 Sep;23(9):1024-9.

114. Dani C, Bertini G, Pezzati M, Cecchi A, Caviglioli C, Rubaltelli FF. Early extubation and nasal continuous positive airway pressure after surfactant treatment for respiratory distress syndrome among preterm infants $<30$ weeks' gestation. Pediatrics. 2004 Jun;113(6):e560-3.

115. Polin RA, Carlo WA. Committee on Fetus and Newborn, American Academy of Pediatrics. Surfactant replacement therapy for preterm and term neonates with respiratory distress. Pediatrics. 2014 Jan;133(1):156-63.

116. Stevens TP, Harrington EW, Blennow M. Soll RF. Early surfactant administration with brief ventilation vs. selective surfactant and continued mechanical ventilation for preterm infants with or at risk for respiratory distress syndrome. Cochrane Database Syst Rev. 2007:4:CD003063.

117. Herting E. Less invasive surfactant administration (LISA) - ways to deliver surfactant in spontaneously breathing infants. Early Hum Dev. 2013 Nov:89(11):875-80.

118. Göpel W, Kribs A, Härtel C, Avenarius S, Teig N, Groneck P, et al. Less invasive surfactant administration is associated with improved pulmonary outcomes in spontaneously breathing preterm infants. Acta Paediatr Oslo Nor 1992. 2015 Mar;104(3):241-6.

119. Göpel W, Kribs A, Ziegler A, Laux R, Hoehn T, Wieg C, et al. Avoidance of mechanical ventilation by surfactant treatment of spontaneously breathing preterm infants (AMV): an open-label, randomised, controlled trial. Lancet Lond Engl. 2011 Nov 5;378(9803):1627-34

120. Flidel-Rimon O, Shinwell ES. Respiratory Distress in the Term and Near-term Infant. NeoReviews. 2005 Jun 1;6(6):e289-97.

121. Reuter S, Moser C, Baack M. Respiratory distress in the newborn. Pediatr Rev. 2014 Oct;35(10):417-428; quiz 429.

122. Conway-Orgel M. Management of hypotension in the very low-birth-weight infant during the golden hour. Adv Neonatal Care Off J Natl Assoc Neonatal Nurses. 2010 Oct;10(5):241-245; quiz 246-247.

123. Bhat BV, Plakkal N. Management of Shock in Neonates. Indian J Pediatr. 2015 Oct;82(10):923-9.

124. Kluckow M, Evans N. Relationship between blood pressure and cardiac output in preterm infants requiring mechanical ventilation. J Pediatr. 1996 Oct;129(4):506-12

125. Pladys $P$, Wodey $E$, Beuchée $A$, Branger $B$, Bétrémieux $P$. Left ventricle output and mean arterial blood pressure in preterm infants during the 1st day of life. Eur J Pediatr. 1999 Oct;158(10):817-24.

126. Groves AM, Kuschel CA, Knight DB, Skinner JR. Relationship between blood pressure and blood flow in newborn preterm infants. Arch Dis Child Fetal Neonatal Ed. 2008 Jan;93(1):F29-32.

127. Okorie ON, Dellinger P. Lactate: biomarker and potential therapeutic target. Crit Care Clin. 2011 Apr;27(2):299-326

128. Kalish BT. Management of Neonatal Hypotension. Neonatal Netw NN. 2017 Jan 1;36(1):40-7.

129. Ballabh P. Pathogenesis and prevention of intraventricular hemorrhage. Clin Perinatol. 2014 Mar;41(1):47-67.

130. Schmidt B, Davis P, Moddemann D, Ohlsson A, Roberts RS, Saigal S, et al. Long-Term Effects of Indomethacin Prophylaxis in Extremely-Low-BirthWeight Infants. N Engl J Med. 2001 Jun 28;344(26):1966-72.
131. Fowlie PW, Davis PG, McGuire W. Prophylactic intravenous indomethacin for preventing mortality and morbidity in preterm infants. Cochrane Database Syst Rev. 2010 Jul 7;7:CD000174.

132. Clyman RI, Saha S, Jobe A, Oh W. Indomethacin Prophylaxis for Preterm Infants: the Impact of Two Multicentered Randomized Controlled Trials on Clinical Practice. J Pediatr. 2007 Jan;150(1):46-50.e2.

133. Kluckow M, Seri I, Evans N. Functional echocardiography: an emerging clinical tool for the neonatologist. J Pediatr. 2007 Feb;150(2):125-30.

134. Kluckow M, Seri I, Evans N. Echocardiography and the neonatologist. Pediatr Cardiol. 2008 Nov;29(6):1043-7.

135. Fugelseth D. Measuring superior vena cava flow as part of echocardiography examinations performed by neonatologists. Acta Paediatr Oslo Nor 1992. 2017 Jan;106(1):5-6.

136. McGovern M, Miletin J. A review of superior vena cava flow measurement in the neonate by functional echocardiography. Acta Paediatr Oslo Nor 1992. 2017 Jan;106(1):22-9.

137. Ficial B, Finnemore AE, Cox DJ, Broadhouse KM, Price AN, Durighel G, et al. Validation Study of the Accuracy of Echocardiographic Measurements of Systemic Blood Flow Volume in Newborn Infants. J Am Soc Echocardiogr. 2013 Dec;26(12):1365-71.

138. Kumagai T, Higuchi R, Higa A, Tsuno Y, Hiramatsu C, Sugimoto T, et al. Correlation between echocardiographic superior vena cava flow and shortterm outcome in infants with asphyxia. Early Hum Dev. 2013 May;89(5):307-10.

139. Jain A, McNamara PJ. Persistent pulmonary hypertension of the newborn: Advances in diagnosis and treatment. Semin Fetal Neonatal Med. 2015 Aug; 20(4):262-71.

140. D'Alto M, Romeo E, Argiento P, Di Salvo G, Badagliacca R, Cirillo AP, et al. Pulmonary arterial hypertension: the key role of echocardiography. Echocardiogr Mt Kisco N. 2015 Jan;32(Suppl 1):S23-37.

141. Sharma V, Berkelhamer S, Lakshminrusimha S. Persistent pulmonary hypertension of the newborn. Matern Health Neonatol Perinatol. 2015;1:14.

142. Bendapudi P, Rao GG, Greenough A. Diagnosis and management of persistent pulmonary hypertension of the newborn. Paediatr Respir Rev. 2015 Jun;16(3):157-61.

143. Nair J, Lakshminrusimha S. Update on PPHN: mechanisms and treatment. Semin Perinatol. 2014 Mar;38(2):78-91.

144. WHO | Baby-Friendly Hospital Initiative [Internet]. WHO. [cited 2016 Jul 14]. Available from: http://www.who.int/nutrition/publications/infantfeeding/ bfhi_trainingcourse/en/

145. Aggarwal R, Deorari AK, Paul VK. Fluid and electrolyte management in term and preterm neonates. Indian J Pediatr. 2001 Dec;68(12):1139-42.

146. Chawla D, Agarwal R, Deorari AK, Paul VK. Fluid and electrolyte management in term and preterm neonates. Indian J Pediatr. 2008 Mar; 75(3):255-9.

147. Bell EF, Acarregui MJ. Restricted versus liberal water intake for preventing morbidity and mortality in preterm infants. Cochrane Database Syst Rev. 2014:12:CD000503.

148. Shaffer SG, Weismann DN. Fluid requirements in the preterm infant. Clin Perinatol. 1992 Mar;19(1):233-50.

149. Civardi E, Tzialla C, Garofoli F, Mazzucchelli I, Bollani L, Stronati M. Nutritional needs of premature infants. J Matern Fetal Neonatal Med. 2011 Oct 1; 24(sup1):27-9.

150. Ziegler EE, Carlson SJ. Early nutrition of very low birth weight infants. J Matern Fetal Neonatal Med. 2009 Jan 1;22(3):191-7.

151. Adamkin DH, Radmacher PG. Current trends and future challenges in neonatal parenteral nutrition. J Neonatal-Perinat Med. 2014 Jan 1;7(3):157-64.

152. te Braake FWJ, van den Akker CHP, Riedijk MA, van Goudoever JB. Parenteral amino acid and energy administration to premature infants in early life. Semin Fetal Neonatal Med. 2007 Feb;12(1):11-8

153. Poindexter BB, Langer JC, Dusick AM, Ehrenkranz RA. National Institute of Child Health and Human Development Neonatal Research Network. Early provision of parenteral amino acids in extremely low birth weight infants: relation to growth and neurodevelopmental outcome. J Pediatr. 2006 Mar:148(3):300-5.

154. Trivedi A, Sinn JKH. Early versus late administration of amino acids in preterm infants receiving parenteral nutrition. Cochrane Database Syst Rev. 2013;7:CD008771.

155. Khanam S, Khan J, Sharma D, Chawla D, Murki S. Nutritional bundle to improve growth outcomes among very low birth weight infants. J MaternFetal Neonatal Med Off J Eur Assoc Perinat Med Fed Asia Ocean Perinat Soc Int Soc Perinat Obstet. 2015;28(15):1851-5. 
156. Chabra S. Management of Gastroschisis: Prenatal, Perinatal, and Neonatal. NeoReviews. 2006 Aug 1;7(8):e419-27.

157. Sharma D, Farahbakhsh N, Shastri S, Sharma P. Intrauterine growth restriction - part 2. J Matern Fetal Neonatal Med. 2016 Mar 15;0(0):1-12.

158. Dani C, Poggi C. Nutrition and bronchopulmonary dysplasia. J Matern Fetal Neonatal Med. 2012 Oct 1:25(sup3):37-40.

159. Zhou W, Yu J, Wu Y, Zhang H. Hypoglycemia incidence and risk factors assessment in hospitalized neonates. J Matern-Fetal Neonatal Med Off J Eur Assoc Perinat Med Fed Asia Ocean Perinat Soc Int Soc Perinat Obstet. 2015 Mar;28(4):422-5.

160. Staffler A, Klemme M, Mola-Schenzle E, Mittal R, Schulze A, Flemmer AW. Very low birth weight preterm infants are at risk for hypoglycemia once on total enteral nutrition. J Matern Fetal Neonatal Med. 2013 Sep 1;26(13):1337-41.

161. Adamkin DH. Neonatal hypoglycemia. Curr Opin Pediatr. 2016 Apr;28(2): $150-5$.

162. Thompson-Branch A, Havranek T. Neonatal Hypoglycemia. Pediatr Rev. 2017 Apr;38(4):147-57.

163. Committee on Fetus and Newborn, Adamkin DH. Postnatal glucose homeostasis in late-preterm and term infants. Pediatrics. 2011 Mar;127(3): 575-579.

164. Adamkin DH. Neonatal hypoglycemia. Semin Fetal Neonatal Med. 2017 Feb; 22(1):36-41.

165. Weston PJ, Harris DL, Battin M, Brown J, Hegarty JE, Harding JE. Oral dextrose gel for the treatment of hypoglycaemia in newborn infants. Cochrane Database Syst Rev. 2016 May 4;5:CD011027.

166. Beardsall K, Vanhaesebrouck S, Ogilvy-Stuart AL, Vanhole C, Palmer CR, van Weissenbruch $M$, et al. Early insulin therapy in very-low-birth-weight infants. N Engl J Med. 2008 Oct 30;359(18):1873-84.

167. Lozano R, Naghavi M, Foreman K, Lim S, Shibuya K, Aboyans V, et al. Global and regional mortality from 235 causes of death for 20 age groups in 1990 and 2010: a systematic analysis for the Global Burden of Disease Study 2010. Lancet. 2012 Dec 15;380(9859):2095-128.

168. Rajaratnam JK, Marcus JR, Flaxman AD, Wang H, Levin-Rector A, Dwyer L, et al. Neonatal, postneonatal, childhood, and under-5 mortality for 187 countries, 1970-2010: a systematic analysis of progress towards Millennium Development Goal 4. Lancet. 2010 Jun 5;375(9730):1988-2008.

169. Wang H, Liddell CA, Coates MM, Mooney MD, Levitz CE, Schumacher AE, et al. Global, regional, and national levels of neonatal, infant, and under-5 mortality during 1990-2013: a systematic analysis for the Global Burden of Disease Study 2013. Lancet. 2014 Sep 13;384(9947):957-79.

170. Sharma D, Kumar C, Pandita A, Pratap OT, Dasi T, Murki S. Bacteriological profile and clinical predictors of ESBL neonatal sepsis. J Matern-Fetal Neonatal Med Off J Eur Assoc Perinat Med Fed Asia Ocean Perinat Soc Int Soc Perinat Obstet. 2016 Feb;29(4):567-70.

171. Camacho-Gonzalez A, Spearman PW, Stoll BJ. Neonatal infectious diseases: evaluation of neonatal sepsis. Pediatr Clin North Am. 2013 Apr:60(2):367-89.

172. Sharma D, Sharma P, Soni P, Gupta B. Ralstonia picketti neonatal sepsis: a case report. BMC Res Notes. 2017 Jan 7;10(1):28.

173. Sharma D, Patel A, Soni P, Sharma P, Gupta B. Empedobacter brevis Meningitis in a Neonate: A Very Rare Case of Neonatal Meningitis and Literature Review. Case Rep Pediatr. 2016;2016:7609602.

174. Sharma D, Patel A, Soni P, Shastri S, Singh R. Leminorella sepsis in very low birth weight neonate as cause of neonatal mortality. J Matern-Fetal Neonatal Med Off J Eur Assoc Perinat Med Fed Asia Ocean Perinat Soc Int Soc Perinat Obstet. 2016 Jun;29:1-3.

175. Sharma D, Dasi T, Murki S, Oleti TP. Kluyvera ascorbata sepsis in an extremely low birth weight infant. Indian J Med Microbiol. 2015 Sep;33(3):437-9.

176. Sharma D, Shastri S. Lactoferrin and neonatology - role in neonatal sepsis and necrotizing enterocolitis: present, past and future. J Matern-Fetal Neonatal Med Off J Eur Assoc Perinat Med Fed Asia Ocean Perinat Soc Int Soc Perinat Obstet. 2016 Mar;29(5):763-70.

177. Kirpal H, Gathwala G, Chaudhary U, Sharma D. Prophylactic fluconazole in very low birth weight infants admitted to neonatal intensive care unit: randomized controlled trial. J Matern-Fetal Neonatal Med Off J Eur Assoc Perinat Med Fed Asia Ocean Perinat Soc Int Soc Perinat Obstet. 2016 Feb;29(4):624-8.

178. Sharma DK, Gathwala G, Shastri S. Chlorhexidine- A novel intervention to decrease the nursery stay and antibiotic exposure duration- randomized trial. J Matern-Fetal Neonatal Med Off J Eur Assoc Perinat Med Fed Asia Ocean Perinat Soc Int Soc Perinat Obstet. 2014 Dec;1:1-21.
179. Sharma D, Gathwala G. Impact of chlorhexidine cleansing of the umbilical cord on cord separation time and neonatal mortality in comparison to dry cord care - a nursery-based randomized controlled trial. J Matern-Fetal Neonatal Med Off J Eur Assoc Perinat Med Fed Asia Ocean Perinat Soc Int Soc Perinat Obstet. 2014 Aug;27(12):1262-5.

180. Gathwala G, Sharma D, Bhakhri B. kiran. Effect of topical application of chlorhexidine for umbilical cord care in comparison with conventional dry cord care on the risk of neonatal sepsis: a randomized controlled trial. J Trop Pediatr. 2013 Jun;59(3):209-13.

181. Shepherd EG, Kelly TJ, Vinsel JA, Cunningham DJ, Keels E, Beauseau W, et al. Significant Reduction of Central-Line Associated Bloodstream Infections in a Network of Diverse Neonatal Nurseries. J Pediatr. 2015 Jul;167(1):41-46.e1-3.

182. Walz JM, Ellison RT, Mack DA, Flaherty HM, Mcllwaine JK, Whyte KG, et al. The bundle "plus": the effect of a multidisciplinary team approach to eradicate central line-associated bloodstream infections. Anesth Analg. 2015 Apr;120(4):868-76.

183. Fisher D, Cochran KM, Provost LP, Patterson J, Bristol T, Metzguer K, et al. Reducing central line-associated bloodstream infections in North Carolina NICUs. Pediatrics. 2013 Dec;132(6):e1664-71.

184. Taylor JE, McDonald SJ, Tan K. Prevention of central venous catheter-related infection in the neonatal unit: a literature review. J Matern Fetal Neonatal Med. 2015 Jul 3;28(10):1224-30.

185. Benitz WE, Gould JB, Druzin ML. Risk factors for early-onset group B streptococcal sepsis: estimation of odds ratios by critical literature review. Pediatrics. 1999 Jun;103(6):e77.

186. Lee SYR, Leung CW. Histological chorioamnionitis - implication for bacterial colonization, laboratory markers of infection, and early onset sepsis in very-low-birth-weight neonates. J Matern-Fetal Neonatal Med Off J Eur Assoc Perinat Med Fed Asia Ocean Perinat Soc Int Soc Perinat Obstet. 2012 Apr;25(4):364-8.

187. Yallapragada SG, Mestan KK, Ernst LM. The Placenta as a Diagnostic Tool for the Neonatologist. NeoReviews. 2016 Mar 1;17(3):e131-43.

188. Queiros da Mota V, Prodhom G, Yan P, Hohlfheld P, Greub G, Rouleau C. Correlation between placental bacterial culture results and histological chorioamnionitis: a prospective study on 376 placentas. J Clin Pathol. 2013 Mar;66(3):243-8.

189. Lamba M, Sharma R, Sharma D, Choudhary M, Maheshwari RK. Bacteriological spectrum and antimicrobial susceptibility pattern of neonatal septicaemia in a tertiary care hospital of North India. J Matern-Fetal Neonatal Med Off J Eur Assoc Perinat Med Fed Asia Ocean Perinat Soc Int Soc Perinat Obstet. 2016 Dec;29(24):3993-8.

190. Bauserman MS, Laughon MM, Hornik CP, Smith PB, Benjamin DK, Clark RH, et al. Group B Streptococcus and Escherichia coli infections in the intensive care nursery in the era of intrapartum antibiotic prophylaxis. Pediatr Infect Dis J. 2013 Mar;32(3):208-12.

191. Schrag SJ, Farley MM, Petit S, Reingold A, Weston EJ, Pondo T, et al. Epidemiology of Invasive Early-Onset Neonatal Sepsis, 2005 to 2014. Pediatrics. 2016 Dec;138(6).

192. Stoll BJ, Hansen NI, Sánchez PJ, Faix RG, Poindexter BB, Van Meurs KP, et al. Early onset neonatal sepsis: the burden of group B Streptococcal and E. coli disease continues. Pediatrics. 2011 May;127(5):817-26.

193. Verani JR, McGee L, Schrag SJ, Division of Bacterial Diseases, National Center for Immunization and Respiratory Diseases, Centers for Disease Control and Prevention (CDC). Prevention of perinatal group B streptococcal disease-revised guidelines from CDC, 2010. MMWR Recomm Rep Morb Mortal Wkly Rep Recomm Rep. 2010 Nov 19;59(RR-10):1-36.

194. Brady MT, Polin RA. Prevention and management of infants with suspected or proven neonatal sepsis. Pediatrics. 2013 Jul;132(1):166-8.

195. Polin RA. Committee on Fetus and Newborn. Management of neonates with suspected or proven early-onset bacterial sepsis. Pediatrics. 2012 May;129(5):1006-15.

196. Gerdes JS. Diagnosis and management of bacterial infections in the neonate. Pediatr Clin North Am. 2004 Aug;51(4):939-959, viii-ix.

197. Gerdes JS, Polin R. Early diagnosis and treatment of neonatal sepsis. Indian J Pediatr. 1998 Feb;65(1):63-78.

198. Riskin A, Aloni Y, Kugelman A, Toropine A, Said W, Bader D. Evaluation and Management of Newborns with Suspected Early-Onset Sepsis: Comparison of Two Approaches and Suggestion for Guidelines. Am J Perinatol. 2017 Mar;34(4):315-22 
199. Sharma D, Farahbakhsh N, Shastri S, Sharma P. Biomarkers for diagnosis of neonatal sepsis: a literature review. J Matern-Fetal Neonatal Med Off J Eur Assoc Perinat Med Fed Asia Ocean Perinat Soc Int Soc Perinat Obstet. 2017 May; $7: 1-14$.

200. Cleminson J, Austin N, McGuire W. Prophylactic systemic antifungal agents to prevent mortality and morbidity in very low birth weight infants. Cochrane Database Syst Rev. 2015;10:CD003850.

201. Ericson JE, Benjamin DK. Fluconazole prophylaxis for prevention of invasive candidiasis in infants. Curr Opin Pediatr. 2014 Apr;26(2):151-6.

202. Hope WW, Castagnola E, Groll AH, Roilides E, Akova M, Arendrup MC, et al. ESCMID* guideline for the diagnosis and management of Candida diseases 2012: prevention and management of invasive infections in neonates and children caused by Candida spp. Clin Microbiol Infect Off Publ Eur Soc Clin Microbiol Infect Dis. 2012 Dec;18(Suppl 7):38-52.

203. Kimberlin DW, Baley J. Committee on infectious diseases, Committee on fetus and newborn. Guidance on management of asymptomatic neonates born to women with active genital herpes lesions. Pediatrics. 2013 Feb;131(2):e635-46.

204. James SH, Kimberlin DW. Neonatal herpes simplex virus infection: epidemiology and treatment. Clin Perinatol. 2015 Mar;42(1):47-59, viii.

205. Waggoner-Fountain LA, Grossman LB. Herpes Simplex Virus. Pediatr Rev. 2004 Mar 1;25(3):86-93.

206. Policy \& Guidelines | National AIDS Control Organization | MoHFW | Gol [Internet]. [cited 2017 Jul 4]. Available from: http://naco.gov.in/documents/ policy-guidelines

207. Neu N, Duchon J, Zachariah P. TORCH infections. Clin Perinatol. 2015 Mar;42(1):77-103, viii

208. Cotten CM. Antibiotic stewardship: reassessment of guidelines for management of neonatal sepsis. Clin Perinatol. 2015 Mar;42(1):195-206, X.

209. Crnich CJ, Jump R, Trautner B, Sloane PD, Mody L. Optimizing Antibiotic Stewardship in Nursing Homes: A Narrative Review and Recommendations for Improvement. Drugs Aging. 2015 Sep;32(9):699-716.

210. Gangat MA, Hsu JL. Antibiotic stewardship: a focus on ambulatory care. S D Med J S D State Med Assoc. 2015;Spec No:44-8.

211. Azra Haider B, Bhutta ZA. Birth asphyxia in developing countries: current status and public health implications. Curr Probl Pediatr Adolesc Health Care. 2006 Jun;36(5):178-88.

212. Costello AM, Manandhar DS. Perinatal asphyxia in less developed countries. Arch Dis Child Fetal Neonatal Ed. 1994 Jul;71(1):F1-3.

213. Azzopardi DV, Strohm B, Edwards AD, Dyet L, Halliday HL, Juszczak E, et al. Moderate hypothermia to treat perinatal asphyxial encephalopathy. N Engl J Med. 2009 Oct 1;361(14):1349-58.

214. Shankaran S, Laptook AR, Ehrenkranz RA, Tyson JE, McDonald SA, Donovan $E F$, et al. Whole-body hypothermia for neonates with hypoxic-ischemic encephalopathy. N Engl J Med. 2005 Oct 13;353(15):1574-84.

215. Shankaran S. Therapeutic Hypothermia for Neonatal Encephalopathy. Curr Treat Options Neurol. 2012 Dec;14(6):608-19.

216. Shankaran S. Hypoxic-ischemic encephalopathy and novel strategies for neuroprotection. Clin Perinatol. 2012 Dec;39(4):919-29.

217. Shankaran S. Current status of hypothermia for hypoxemic ischemia of the newborn. Indian J Pediatr. 2014 Jun;81(6):578-84.

218. Shankaran S, Laptook A, Wright LL, Ehrenkranz RA, Donovan EF, Fanaroff AA et al. Whole-body hypothermia for neonatal encephalopathy: animal observations as a basis for a randomized, controlled pilot study in term infants. Pediatrics. 2002 Aug;110(2 Pt 1):377-85.

219. Shankaran S, Laptook AR. Hypothermia as a treatment for birth asphyxia. Clin Obstet Gynecol. 2007 Sep;50(3):624-35.

220. da Silva S, Hennebert N, Denis R, Wayenberg JL. Clinical value of a single postnatal lactate measurement after intrapartum asphyxia. Acta Paediatr Oslo Nor 1992. 2000 Mar:89(3):320-3.

221. Shah S, Tracy M, Smyth J. Postnatal lactate as an early predictor of shortterm outcome after intrapartum asphyxia. J Perinatol Off J Calif Perinat Assoc. 2004 Jan;24(1):16-20.

222. Chiang M-C, Lien R, Chu S-M, Yang P-H, Lin J-J, Hsu J-F, et al. Serum Lactate, Brain Magnetic Resonance Imaging and Outcome of Neonatal Hypoxic Ischemic Encephalopathy after Therapeutic Hypothermia. Pediatr Neonatol. 2016 Feb 1;57(1):35-40.

223. Manley BJ, Owen LS, Hooper SB, Jacobs SE, Cheong JLY, Doyle LW, et al. Towards evidence-based resuscitation of the newborn infant. The Lancet. 2017 Apr 22;389(10079):1639-48.
224. Committee on Fetus and Newborn, Papile L-A, Baley JE, Benitz W, Cummings J, Carlo WA, et al. Hypothermia and neonatal encephalopathy. Pediatrics. 2014 Jun;133(6):1146-50.

225. Tagin MA, Woolcott CG, Vincer MJ, Whyte RK, Stinson DA. Hypothermia for neonatal hypoxic ischemic encephalopathy: an updated systematic review and meta-analysis. Arch Pediatr Adolesc Med. 2012 Jun 1;166(6):558-66.

226. Filippi L, Catarzi S, Gozzini E, Fiorini P, Falchi M, Pisano T, et al. Hypothermia for neonatal hypoxic-ischemic encephalopathy: may an early amplitudeintegrated EEG improve the selection of candidates for cooling? J MaternFetal Neonatal Med Off J Eur Assoc Perinat Med Fed Asia Ocean Perinat Soc Int Soc Perinat Obstet. 2012 Nov;25(11):2171-6.

227. Youn Y-A, Kim JH, Yum S-K, Moon C-J, Lee I-G, Sung IK. The hospital outcomes compared between the early and late hypothermia-treated groups in neonates. J Matern Fetal Neonatal Med. 2016 Jul 17;29(14):2288-92.

228. Shankaran S, Pappas A, McDonald SA, Vohr BR, Hintz SR, Yolton K, et al. Childhood outcomes after hypothermia for neonatal encephalopathy. N Engl J Med. 2012 May 31;366(22):2085-92.

229. Jacobs SE, Berg M, Hunt R, Tarnow-Mordi WO, Inder TE, Davis PG. Cooling for newborns with hypoxic ischaemic encephalopathy. Cochrane Database Syst Rev. 2013;1:CD003311.

230. Sarkar S, Barks JD. Systemic complications and hypothermia. Semin Fetal Neonatal Med. 2010 Oct;15(5):270-5.

231. Alamo L, Vial Y, Gengler C, Meuli R. Imaging findings of bronchial atresia in fetuses, neonates and infants. Pediatr Radiol. 2016 Mar;46(3):383-90.

232. Vellanki H, Antunes M, Locke RG, McGreevy T, Mackley A, Eubanks JJ, et al. Decreased incidence of pneumothorax in VLBW infants after increased monitoring of tidal volumes. Pediatrics. 2012 Nov;130(5):e1352-8.

233. Boo N-Y, Cheah IG-S, Registry MNN. Risk factors associated with pneumothorax in Malaysian neonatal intensive care units. J Paediatr Child Health. 2011 Apr;47(4):183-90.

234. Miller JD, Carlo WA. Pulmonary complications of mechanical ventilation in neonates. Clin Perinatol. 2008 Mar;35(1):273-281, x-xi.

235. Raju U, Sondhi V, Patnaik SK. Meconium Aspiration Syndrome: An Insight. Med J Armed Forces India. 2010 Apr;66(2):152-7.

236. Murki S, Kumar P. Blood exchange transfusion for infants with severe neonatal hyperbilirubinemia. Semin Perinatol. 2011 Jun;35(3):175-84.

237. Doyle KJ, Bradshaw WT. Sixty golden minutes. Neonatal Netw NN. 2012 Oct;31(5):289-94.

238. Kooi EMW, Verhagen EA, Elting JWJ, Czosnyka M, Austin T, Wong FY, et al. Measuring cerebrovascular autoregulation in preterm infants using nearinfrared spectroscopy: an overview of the literature. Expert Rev Neurother. 2017 Jun;29:1-18

239. Beck J, Loron G, Masson C, Poli-Merol M-L, Guyot E, Guillot C, et al. Monitoring Cerebral and Renal Oxygenation Status during Neonatal Digestive Surgeries Using Near Infrared Spectroscopy. Front Pediatr. 2017:5:140.

240. Votava-Smith JK, Statile CJ, Taylor MD. King EC. Nelson DP, et al. Impaired cerebral autoregulation in preoperative newborn infants with congenital heart disease. J Thorac Cardiovasc Surg: Pratt JM; 2017 May 23.

241. Sood BG, McLaughlin K, Cortez J. Near-infrared spectroscopy: applications in neonates. Semin Fetal Neonatal Med. 2015 Jun;20(3):164-72.

242. Pichler G, Cheung P-Y, Aziz K, Urlesberger B, Schmölzer GM. How to monitor the brain during immediate neonatal transition and resuscitation? A systematic qualitative review of the literature. Neonatology. 2014:105(3):205-10.

243. Pellicer A, Greisen G, Benders M, Claris O, Dempsey E, Fumagalli M, et al. The SafeBoosC phase II randomised clinical trial: a treatment guideline for targeted near-infrared-derived cerebral tissue oxygenation versus standard treatment in extremely preterm infants. Neonatology. 2013;104(3):171-8.

244. Winckworth LC, Raj R, Draper L, Leith W. Antenatal counselling: documentation and recall. J Paediatr Child Health. 2013 May;49(5):422-3.

245. Moreno Hernando J, Thió Lluch M, Salguero García E, Rite Gracia S, Fernández Lorenzo JR, Echaniz Urcelay I, et al. [Recommendations for neonatal transport]. An Pediatr Barc Spain 2003. 2013 Aug;79(2):117.e1-7.

246. Rathod D, Adhisivam B, Bhat BV. Transport of sick neonates to a tertiary care hospital, South India: condition at arrival and outcome. Trop Doct. 2015 Apr:45(2):96-9.

247. Kumar PP, Kumar CD, Shaik F, Yadav S, Dusa S, Venkatlakshmi A. Transported neonates by a specialist team - how STABLE are they. Indian J Pediatr. 2011 Jul;78(7):860-2. 
248. Kumutha J, Rao GV, Sridhar BN, Vidyasagar D. The GVK EMRI maternal and neonatal transport system in India: a mega plan for a mammoth problem. Semin Fetal Neonatal Med. 2015;20(5):326-34. doi:10.1016/j.siny.2015.07.003. Epub 2015 Jul 23. Review. PubMed PMID: 26212526.

249. Ashmeade TL, Haubner L, Collins S, Miladinovic B, Fugate K. Outcomes of a Neonatal Golden Hour Implementation Project. Am J Med Qual Off J Am Coll Med Qual. 2016 Feb;31(1):73-80.

250. Castrodale V, Rinehart S. The golden hour: improving the stabilization of the very low birth-weight infant. Adv Neonatal Care Off J Natl Assoc Neonatal Nurses. 2014 Feb;14(1):9-14; quiz 15-16.

251. Reuter S, Messier S, Steven D. The neonatal Golden Hour-intervention to improve quality of care of the extremely low birth weight infant. S D Med J S D State Med Assoc. 2014 Oct;67(10):397-403, 405.

Submit your next manuscript to BioMed Central and we will help you at every step:

- We accept pre-submission inquiries

- Our selector tool helps you to find the most relevant journal

- We provide round the clock customer support

- Convenient online submission

- Thorough peer review

- Inclusion in PubMed and all major indexing services

- Maximum visibility for your research

Submit your manuscript at www.biomedcentral.com/submit
Biomed Central 